\title{
Modeling the Dynamic Vegetation-Climate System over China Using a Coupled Regional Model
}

\author{
YING SHI \\ National Climate Center, China Meteorological Administration, Beijing, China, and Department of Civil and Environmental \\ Engineering, and Center for Environmental Sciences and Engineering, University of Connecticut, Storrs, Connecticut \\ MIAO YU \\ Key Laboratory of Meteorological Disaster of Ministry of Education, and International Joint Laboratory on Climate \\ and Environment Change, Nanjing University of Information Science Technology, Nanjing, China \\ AMIR ERFANIAN AND GUILING WANG \\ Department of Civil and Environmental Engineering, and Center for Environmental Sciences and Engineering, \\ University of Connecticut, Storrs, Connecticut
}

(Manuscript received 26 March 2017, in final form 27 March 2018)

\begin{abstract}
Using the Regional Climate Model (RegCM) coupled with the Community Land Model (CLM) including modules of carbon-nitrogen cycling $(\mathrm{CN})$ and vegetation dynamics (DV), this study evaluates the performance of the model with different capacity of representing vegetation processes in simulating the present-day climate over China based on three 21-yr simulations driven with boundary conditions from the ERA-Interim reanalysis data during 1989-2009. For each plant functional type (PFT), the plant pheonology, density, and fractional coverage in RegCM-CLM are all prescribed as static from year to year; RegCM-CLM-CN prescribes static fractional coverage but predicts plant phenology and density, and RegCM-CLM-CN-DV predicts plant phenology, density, and fractional coverage. Compared against the observational data, all three simulations reproduce the present-day climate well, including the wind fields, temperature and precipitation seasonal cycles, extremes, and interannual variabilities. Relative to RegCM-CLM, both RegCM-CLM-CN and RegCM-CLM-CN-DV perform better in simulating the interannual variability of temperature and spatial distribution of mean precipitation, but produce larger biases in the mean temperature field. RegCM-CLM-CN overestimates leaf area index (LAI), which enhances the cold biases and alleviates the dry biases found in RegCM-CLM. RegCM-CLM-CN-DV underestimates vegetation cover and/or stature, and hence overestimates surface albedo, which enhances the wintertime cold and dry biases found in RegM-CLM. During summer, RegCM-CLM-CN-DV overestimates LAI in south and east China, which enhances the cold biases through increased evaporative cooling; in the west where evaporation is low, the albedo effect of the underestimated vegetation cover is still dominant, leading to enhanced cold biases relative to RegCM-CLM.
\end{abstract}

\section{Introduction}

Vegetation-atmosphere interaction is an important process in climate systems. On one hand, vegetation distribution and structure are determined primarily by climate (Neilson 1986; Woodward 1987; Lu et al. 2001; Stenseth et al. 2002; Nemani et al. 2003); on the other hand, vegetation affects the land surface biogeophysical properties (e.g., albedo, roughness height, Bowen ratio)

Corresponding authors: Ying Shi, shiying@cma.gov.cn; Miao Yu, yum@nuist.edu.cn and hence determines the surface net radiation and its partitioning between latent and sensible heat fluxes (Pielke et al. 1998; McPherson 2007; Bonan 2008; Delire et al. 2011; Swann et al. 2012), which then further influence regional climate.

Comprehensive representation for the biogeophysical effects of vegetation on water and energy fluxes between land and atmosphere in general circulation models (GCMs) can be traced back to the land surface models (LSMs) of Dickinson et al. (1986) and Sellers et al. (1986), which have been used in numerous studies investigating the impact of prescribed land-cover changes 
on regional and global climate. The development of dynamic global vegetation models (DGVMs) [e.g., IBIS, Foley et al. (1996); TRIFFID, Cox et al. (2000); Lund Potsdam Jena (LPJ), Sitch et al. (2003)] and their coupling with land surface and climate models improved the climate models' capacity to more realistically represent the coupled dynamic land-atmosphere system, accounting for both the response of terrestrial ecosystems and its impact on climate variation/changes. For example, Foley et al. (1998) coupled the IBIS dynamic global vegetation model with an atmospheric general circulation model [Global Environmental and Ecological Simulation of Interactive Systems (GENESIS)], Wang and Eltahir (2000) coupled IBIS to a zonally symmetric atmospheric model, Bonan et al. (2003) coupled LPJ to the land component of a climate model (NCAR LSM), and O'ishi et al. (2009) coupled LPJ with the MIROC atmospheric general circulation model. The past decade has witnessed rapid development along this direction, as the climate modeling tools transition from GCMs to Earth system models (ESMs). As a result, dynamic vegetation representation was already included in several models participating in phase 5 of the Coupled Model Intercomparison Project (CMIP5; Taylor et al. 2012).

The importance of vegetation-climate feedback has been recognized for several decades already. For example, Charney (1975) argued that the effect of vegetation reduction on climate may have triggered a positive feedback, contributing to the persistence of the twentieth-century Sahel drought. Schwartz and Karl (1990) indicated that the "green-up" period of vegetation significantly impacts the extreme surface temperature in the central and eastern United States. Wu et al. (2016) found that the vegetation-mediated feedbacks dampen the projected warming trend and enhance the projected rainfall decrease over the African rain forest areas. Tölle et al. (2017) found that abrupt conversion from forest to grassland cover leads to a decline in evapotranspiration and precipitation and a significant warming as a result of reduced latent heat flux over Southeast Asia. Relative to global climate models with prescribed vegetation, those with dynamic vegetation showed improved performance in capturing the lowfrequency variability of precipitation in semiarid regions (Wang 2004; Wang et al. 2011; Delire et al. 2004, 2011), and projected dramatically different future climate with a dieback of the Amazon forest (Cox et al. 2000). Liu et al. (2006) found positive feedback of vegetation on temperature in boreal regions and on precipitation in some specific areas of the tropics, a finding that was corroborated by Jiang et al. (2011) using an asynchronously coupled climate-biosphere model IAP-AGCMBIOMES. Different projections for the summer monsoon in Asia can be derived if using the HadGEM2 model coupled with a dynamic vegetation model (Martin and Levine 2012; Cho et al. 2015).

For some specific regions like China, which encompasses major mountainous regions with some of the most complex topography of the world, major deficiencies of GCMs have been documented and coarse resolution has been suggested as the primary cause (e.g., Jiang et al. 2005; Gao et al. 2006; Xu et al. 2010). To improve the simulation of this regional climate, nested high-resolution regional climate models (RCMs) have been frequently used (e.g., Gao et al. 2001; X. J. Gao et al. 2008, 2012; Yu et al. 2010; Zou and Zhou 2013). Similar to GCMs, for realistic simulation of the presentday climate and reliable projection of the future using RCMs, it is important that we understand the role of vegetation in the regional climate system. This necessitates RCMs with embedded predictive vegetation models (e.g., R. Gao et al. 2008; Winter et al. 2009; Wang et al. 2016; Wu et al. 2017).

Limited by the lack of model capacity to simulate vegetation dynamics or phenology processes, most past studies on land-atmosphere interactions over the China domain were based on models with prescribed vegetation or prescribed vegetation changes. For example, Fu and Yuan (2001) carried out two experiments with the Regional Integrated Environment Model System (RIEMS) and found that changing the present vegetation cover to the potential natural vegetation in large scale would enhance the summer monsoon over East Asia and bring more moisture to a larger portion of East Asia, resulting in an increase of atmospheric moisture content and precipitation as well as soil moisture. Results from Gao et al. (2007) suggested that historical land use may have enhanced annual mean precipitation and decreased annual mean temperature over south China, and decreased precipitation over north China, through strengthening the monsoon circulation and changing the surface energy budget. Others studied the impacts of changes of specific type of vegetation or changes in several climate sensitive areas. For example, Xue (1996) investigated the impact of desertification in Mongolian and Inner Mongolian grassland and found that desertification can alter the surface energy balance, which enhances sinking motion (or weakens rising motion) over the desertification area because of the reduction of convective latent heating above the surface layer. Impacts of deforestation in south China and reforestation in the northwest arid region were investigated by Zheng et al. (2002a,b) and Ding et al. (2005), respectively. Their results showed that deforestation in south China could lead to a decrease (increase) of precipitation in north (south) China while reforestation may cause 
precipitation to increase in the Yellow River basins and decrease over the Yangtze River basins and south China. Agricultural land-use effects on climate over China were studied by Zhang et al. (2010), who found that agricultural changes might have led to a decrease of annual mean temperature in southern China and a seasonally and spatially varying response of precipitation. Gao et al. (2013) found that land degradation over the Guizhou Karst Plateau may have contributed to a local rainfall reduction and temperature increase through reduced net radiation and evaporation. Based on multimodel simulations with different vegetation types in 2000 and 1980, Zhang et al. (2016) presented the theory that expansion of arable land in northeast China can cause a cooling effect. Note that by prescribing vegetation changes, most of these studies represented extreme and idealized cases. Obviously, it is not realistic to completely convert the vegetation cover from one type to another, and land-use changes are often rather dispersed.

The models with dynamic vegetation can simulate transient and spatially heterogeneous changes of vegetation cover and update vegetation distribution on a yearly basis. Several studies on vegetation-atmosphere interaction over China were based on RCMs with dynamic vegetation. For instance, Chen et al. (2004) used a regional coupled soil-vegetation-atmosphere model to study changes caused by atmospheric $\mathrm{CO}_{2}$ concentration increase and found the largest changes and feedbacks between vegetation and climate over northern China (northward of $40^{\circ} \mathrm{N}$ ) where deserts and shrubland were projected to expand because of warmer and drier conditions. In R. Gao et al.'s (2008) study, they coupled the Atmosphere-Vegetation Interaction Model (AVIM) to the regional model RIEMS with version 1.0; the resulting coupled model RIEMS-AVIM with version 2.0 was found by Dan et al. (2015) to reduce both the warming bias (for temperature) and the wet biases (for precipitation) in July in east China compared to the original model RIEMS.

Previous studies with or without dynamic vegetation have shown that the surface temperature and precipitation, the monsoon systems, the surface energy, and water budgets can be directly affected by vegetation feedback (Xue et al. 2010; Wang et al. 2016). Realistic simulation of the coupled vegetation-climate system relies on climate models with dynamic vegetation schemes. Past applications of such models over the China domain involved relatively short model integrations, from several months to a few years [e.g., 7 years in Chen et al. (2004); 18 months in Dan et al. (2015); 10 years in R. Gao et al. (2008)], which is of limited value for understanding the role of vegetation in long-term climate variability and changes. Recently,
Wang et al. (2016) coupled the Community Land Model (CLM) version 4.5 including modules of carbonnitrogen cycling $(\mathrm{CN})$ and vegetation dynamics (DV) with a Regional Climate Model RegCM, version 4.3.4. The resulting model RegCM-CLM-CN-DV was evaluated for performance over tropical Africa (Wang et al. 2016) and was used in future climate projection studies for that region (Yu et al. 2016; Erfanian et al. 2016). As a potential tool with desirable model capacity to predict vegetation and climate, the present study evaluates the coupled model's performance over East Asia including China, and documents the impact of including vegetation dynamics on the present climate of this region using the best possible boundary conditions as derived from the reanalysis data. This will form the basis of follow-up studies on future climate projections for this region using the coupled model driven with boundary conditions from global projection models, and will also help understand potential differences from projections conducted using models with different vegetation treatments. Section 2 of this paper describes the model, data, and experimental design. Validations of the model including surface climate, climate extremes, and interannual variability, as well as results on the impact of $\mathrm{CN}$ and $\mathrm{CN}-\mathrm{DV}$ are described in section 3. A summary and discussion are presented in section 4 .

\section{Model, data, and experimental design}

The model used is the Abdus Salam International Center for Theoretical Physics (ICTP) Regional Climate Model, RegCM4.3.4, coupled with the National Center for Atmospheric Research (NCAR) Community Land Model, version 4.5 (CLM4.5) including modules of $\mathrm{CN}$ and DV (Wang et al. 2016). The RegCM series (Giorgi et al. 1993a,b; Pal et al. 2007; Giorgi et al. 2012) are widely used as regional climate models in China, with a variety of applications including studies of present-day climate simulation, land-use and aerosol effects, climate change projections, and seasonal climate predictions, as well as further developments of the models (e.g., Giorgi et al. 1999; Gao et al. 2001, 2007, 2017; Ju and Wang 2006; Shi et al. 2011; Zou and Zhou 2013; Zhang et al. 2015; Ji et al. 2015). In this study, the model is run at 18 vertical sigma layers with the model top at $50 \mathrm{hPa}$. Based on the performances of the model over China using different combinations of physical parameterizations in a large number of short-term experiments, we chose the atmospheric radiative transfer package of Kiehl et al. (1998), the planetary boundary layer computations based on the nonlocal formulation of Holtslag et al. (1990), the large-scale cloud and precipitation scheme of Pal et al. (2000), and the convection 
scheme of Emanuel (1991). The land surface scheme in the model was developed based on CLM4.0 with surface radiation and gross primary production (GPP) parameterizations from CLM4.5, and also includes a refinement of the stress deciduous phenology in $\mathrm{CN}$ and drought limitation on evergreen trees in DV ( $\mathrm{Yu}$ et al. 2014; Wang et al. 2016). It has been shown that CLM4.0 can capture the climatology and annual cycles of ecological and hydrological variables reasonably well (Lawrence et al. 2011; Gotangco Castillo et al. 2012; Yu et al. 2014)

The phase II East Asia domain of the international Coordinated Regional Climate Downscaling Experiment (CORDEX; Giorgi et al. 2009) is used, which encompasses all of continental China and adjacent areas with a grid spacing of $50 \mathrm{~km}$. Three 21-yr simulations for the period 1989-2009 (hereafter referred to as RegCMCLM, RegCM-CLM-CN, and RegCM-CLM-CN-DV, respectively) driven by ERA-Interim reanalysis data (Uppala et al. 2008) are conducted, which differ in whether the components of $\mathrm{CN}$ and $\mathrm{DV}$ are engaged or not. Specifically, vegetation conditions (including structure, distribution, and phenology) are prescribed in RegCM-CLM, in which leaf area index (LAI) and stem area index (SAI) of each plant functional type (PFT) vary from day to day but their seasonal cycle and PFT fractional coverages remain static from year to year; in RegCM-CLM-CN, the CN component is engaged to predict LAI, SAI, and phenology, while vegetation distribution (in the form of PFT fractional coverages) is prescribed to be static; in RegCM-CLM-CN-DV, both the $\mathrm{CN}$ and DV components are active and thus vegetation structure, distribution, and phenology are all predicted by the model (Yu et al. 2016; Wang et al. 2016). As in Wang et al. (2016), the RegCM-CLM simulation was initialized with an intermediate-wet soil moisture state to reduce the spinup time; the RegCMCLM-CN simulation was initialized with a spunup $\mathrm{CN}$ state provided by NCAR that was derived from an observation-driven long-term CLM-CN integration; and the RegCM-CLM-CN-DV simulation was initialized with spunup vegetation and land surface conditions derived from a 200-yr CLM-CN-DV offline integration driven by the RegCM-CLM climate. The spinup time was 1 year for the RegCM-CLM simulation, and 22 years for the RegCM-CLM-CN and RegCM-CLM-CNDV simulations that involved cycling the 21-yr lateral boundary forcing twice (with output from the last 20 years used for results analysis). For RegCM-CLM-CN$\mathrm{DV}$, this is equivalent to spinning up vegetation for over 220 years under a similar climate.

The observed spatial distribution for different PFTs and LAI derived from the Moderate Resolution
Imaging Spectroradiometer (MODIS) dataset (Lawrence and Chase 2007) and the ERA-Interim reanalysis data are used to evaluate the circulation anomalies. The observation dataset of temperature and precipitation used is CN05.1 (Wu and Gao 2013). CN05.1 is an augmentation of CN05 (Xu et al. 2009) that includes a greater number of station observations. For $\mathrm{CN} 05$ and CN05.1, the interpolation from station to grid data essentially follows the same approach used in generating the Climatic Research Unit dataset (CRU; New et al. 2002). Specifically, a gridded climatology was first calculated using thin-plate smoothing splines and the spline surfaces are fitted as functions, including latitude and longitude as spline variables and elevation as a covariate. The second step is to interpolate the daily anomalies at stations to grids using an angular weighting method. Adding the daily anomalies to the climatology produces the final gridded data. Different spatial resolutions of $0.25^{\circ}, 0.5^{\circ}$, and $1^{\circ}$ are available in CN05.1, of which the $0.5^{\circ}$ resolution is the closest to the model resolution of $50 \mathrm{~km}$ and is therefore used here. To facilitate the comparison of model simulations with observational data, the model outputs are interpolated bilinearly to the CN05.1 grid. The model performance is evaluated using multiple metrics, including the mean bias, temporal and spatial correlation coefficients (TCOR and SCOR), and root-mean-square error (RMSE). The statistical significance test for correlation and differences is performed using the two-tailed Student's $t$ test.

\section{Results}

\section{a. Vegetation and surface properties}

Because of the differences in experimental design, vegetation conditions differ significantly among the three simulations. For example, relative to MODISderived dataset used to prescribe vegetation in RegCM-CLM, LAI in south China in DJF is overestimated by the model with $\mathrm{CN}$ and the model with DV (Figs. 1a,b). The overestimation of LAI extends to most areas of east China in RegCM-CLM-CN in JJA, while the RegCM-CLM-CN-DV model overestimates the LAI primarily in southwest China (Figs. 1c,d).

As vegetation cover is predicted in the model with CN-DV, Table 1 compares the percentage of PFTs and bare soil from the MODIS-derived dataset and RegCMCLM-CN-DV model. The top three observed over China are bare soil $(40 \%)$, crop $(21 \%)$, and cool C3 grass (10\%). The RegCM-CLM-CN-DV model significantly overestimates the fractional coverage of 
(a) LAI diff., DJF, RegCM-CLM-CN

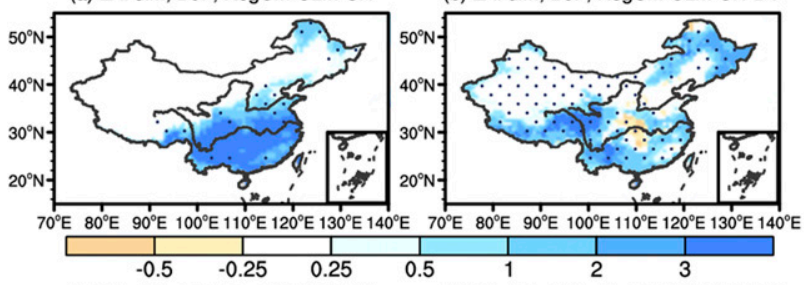

(e) Alb. diff., DJF, RegCM-CLM-CN
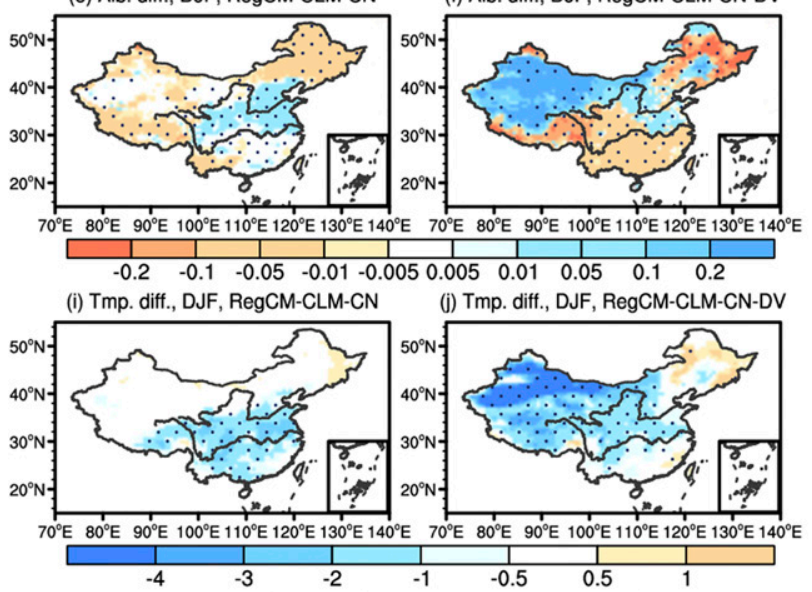

$\begin{array}{lll}\text { (m) Pre. diff., DJF, RegCM-CLM-CN } & \text { (n) Pre. diff., DJF, RegCM-CLM-CN-DV }\end{array}$

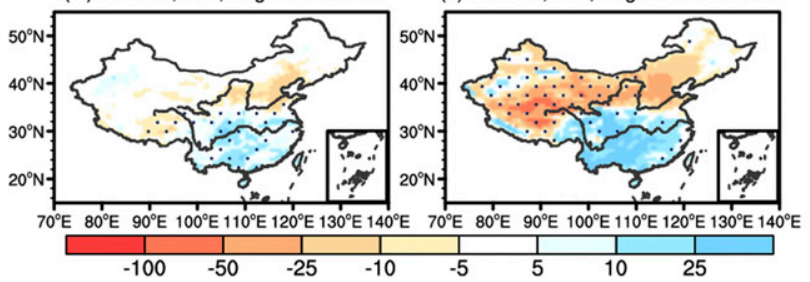

(c) LAI diff., JJA, RegCM-CLM-CN

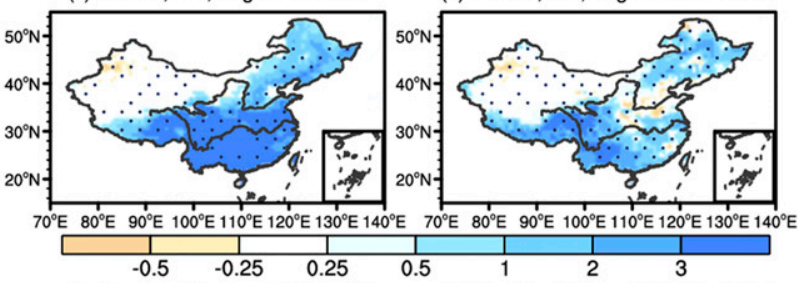

(g) Alb. diff., JJA, RegCM-CLM-CN

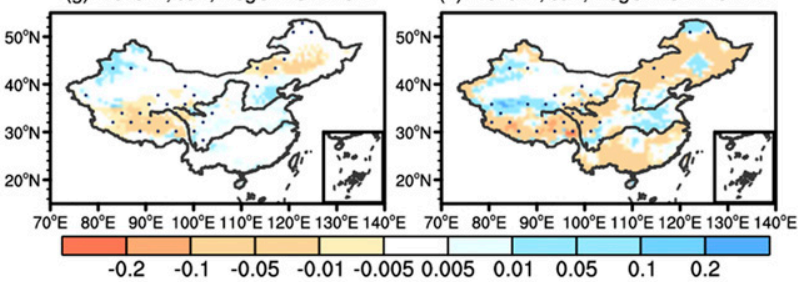

$\begin{array}{lll}\text { (k) Tmp. diff., JJA, RegCM-CLM-CN } & \text { (I) Tmp. diff., JJA, RegCM-CLM-CN-DV }\end{array}$

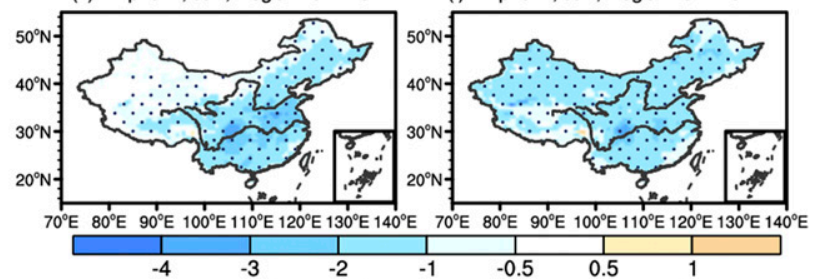

(0) Pre. diff., JJA, RegCM-CLM-CN

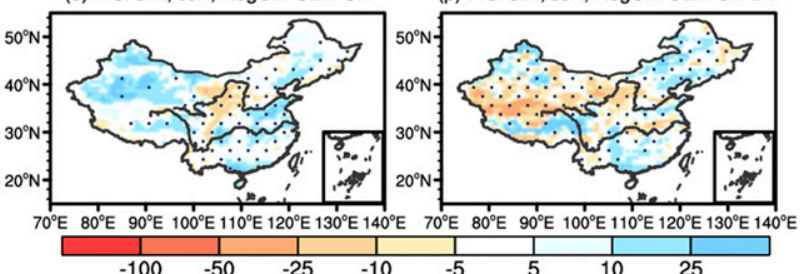

FIG. 1. Impact of carbon-nitrogen dynamics (CN) and vegetation dynamics (DV) on the simulation of (a)-(d) LAI, (e)-(h) surface albedo, (i)-(l) temperature $\left({ }^{\circ} \mathrm{C}\right)$, and $(\mathrm{m})-(\mathrm{p})$ precipitation $(\%)$ in DJF and JJA, as defined by the differences between RegCM-CLM-CN or RegCM-CLM-CN-DV and RegCM-CLM. Black dots indicate areas where the differences are significant at the $95 \%$ confidence level.

needleleaf evergreen boreal trees and broadleaf deciduous temperate trees, and underestimates the fractional coverage of cool C3 grass. The spatial distribution of these model biases are shown in Fig. 2 for four major types of vegetation, based on the RegCM-CLM-CN-DV simulation over the period 1990-2009. Note that the dynamic vegetation model simulates natural vegetation only and does not include crops. Over most of the regions where tree coverage is significantly overestimated, the MODIS land cover is cropland, indicating that the seeming disparity between the model and the MODIS data is caused by land conversion to agriculture. An exception is found over west China including the Tibetan Plateau region where the tree coverage is overestimated at the expense of grassland, which reflects deficiencies of the model in simulating the regional climate and/or potential vegetation. The model performs well in reproducing the fraction and distribution of bare ground (Table 1 and Figs. 2j-1), with two exceptions: a strong underestimation along the Himalaya Mountains and surrounding region caused by model deficiencies, and strong overestimations over the agriculture hotspots in the North Great Plain and northeast China (and the northwestern corner of Xinjiang province in northwest China). Within these agricultural hotspots, the specific locations of the modeled bare ground coincide remarkably well with the dryland irrigation hotspots in China (Zhu et al. 2014), which suggests that natural climate in these areas may only support sparse vegetation cover (consistent with our model results).

Over the large fraction of China where the tree coverage (including both needleleaf evergreen boreal trees and broadleaf deciduous temperate trees) is overestimated (Table 1, Fig. 2c), LAI is overestimated in both DJF and JJA (Figs. 1b,d), leading to lower albedo in RegCM-CLM-CN-DV than in RegCM-CLM (Figs. 1f,h). Elsewhere, albedo is overestimated because 
TABLE 1. Percentage of plant functional types (PFTs) from MODIS-derived dataset and RegCM-CLM-CN-DV simulation (unit: \%). Bold indicates statistically significant difference of PFTs, and "- " indicates no difference. Note that the PFTs in RegCM-CLM and RegCM-CLM-CN are prescribed according to the MODIS-derived dataset, and are therefore not listed in this table.

\begin{tabular}{|c|c|c|c|c|}
\hline PFT & Description & MODIS & RegCM-CLM-CN-DV & Difference \\
\hline 0 & Bare soil & 40 & 45 & 5 \\
\hline 1 & Needleleaf evergreen temperate tree & 6 & 6 & - \\
\hline 2 & Needleleaf evergreen boreal tree & 4 & 15 & 11 \\
\hline 3 & Needleleaf deciduous boreal tree & 0 & 0 & - \\
\hline 4 & Broadleaf evergreen tropical tree & 0 & 0 & - \\
\hline 5 & Broadleaf evergreen temperate tree & 0 & 1 & 1 \\
\hline 6 & Broadleaf deciduous tropical tree & 0 & 0 & - \\
\hline 7 & Broadleaf deciduous temperate tree & 4 & 15 & 11 \\
\hline 8 & Broadleaf deciduous boreal tree & 3 & 5 & 2 \\
\hline 9 & Broadleaf evergreen temperate shrub & 0 & 0 & - \\
\hline 10 & Broadleaf deciduous temperate shrub & 1 & 3 & 2 \\
\hline 11 & Broadleaf deciduous boreal shrub & 2 & 0 & -2 \\
\hline 12 & Arctic C3 grass & 7 & 4 & -3 \\
\hline 13 & Cool C3 grass & 10 & 1 & -9 \\
\hline 14 & warm $\mathrm{C} 4$ grass & 2 & 3 & 1 \\
\hline $15-16$ & Crops & 21 & 0 & -21 \\
\hline
\end{tabular}

of the slight overestimation of bare ground fraction. These differences in surface properties necessarily influence the surface climate (Figs. 1i-p) as described in more detail in section $3 \mathrm{c}$.

\section{b. Atmospheric circulation}

Figure 3 presents the wind fields in boreal winter (DJF) and summer (JJA) at $200 \mathrm{hPa}$ from ERAInterim reanalysis data and from the RegCM-CLM, RegCM-CLM-CN, and RegCM-CLM-CN-DV simulations for the period of 1990-2009. From the reanalysis data, strong westerly wind can be found from the lower reaches of the Yangtze River to the east with the maxima wind speed above $60 \mathrm{~m} \mathrm{~s}^{-1}$ in winter, while greater than $25 \mathrm{~m} \mathrm{~s}^{-1}$ wind (the westerly jet) can be observed over northwest China in summer (Figs. 3a,h). The model generally captures the spatial pattern of the 200-hPa wind, and the SCORs of the wind speed are all larger than 0.98. However, relative to the reanalysis data, the model westerly wind in DJF is weaker north of the jet stream center (around $30^{\circ} \mathrm{N}$ ) and slightly stronger in the south, leading to a cyclonic bias over the eastern part of the domain in all three simulations (Figs. 3e-g); in JJA, the model westerly jet located around $40^{\circ} \mathrm{N}$ is weaker north of the Tibetan Plateau and stronger in the east, with a cyclonic and anticyclonic pattern of wind bias over the Tibetan Plateau and northeast China, respectively (Figs. 31-n). The spatial patterns of the model biases are similar among all three simulations, especially in DJF. But the anticyclonic bias over the Tibetan Plateau is less evident in the simulation with dynamic vegetation than the other two in JJA.
The multiyear mean $850-\mathrm{hPa}$ wind fields from the simulations and from the reanalysis data are presented in Fig. 4. In winter, strong northwesterly wind prevails over north China, with the maximum speed exceeding $12 \mathrm{~m} \mathrm{~s}^{-1}$, and it turns to northeasterly over the south; in summer, the wind reverses and is primarily southwesterly over China (Figs. 4a,h). Compared to the reanalysis data, all three simulations can reproduce the spatial pattern of the low-level wind field in both seasons. The SCORs of the wind speed are fairly high, at $0.74,0.75$, and 0.76 in DJF and 0.86 , 0.87 , and 0.88 in JJA for RegCM-CLM, RegCMCLM-CN, and RegCM-CLM-CN-DV, respectively. However, stronger wind over north China in DJF (Figs. $4 \mathrm{e}-\mathrm{g}$ ) and an anticyclonic bias over the eastern part of the domain in JJA can be found in all three simulations, which will influence precipitation (Figs. 41-n).

\section{c. Surface climate}

\section{1) BOREAL WINTER}

Figure 5 shows the observed mean temperature and precipitation in DJF, and the model biases (model minus observation) simulated by RegCM-CLM, RegCMCLM-CN, and RegCM-CLM-CN-DV over China for the period of 1990-2009. All three simulations can capture the observed latitudinal distribution of temperature in eastern China and the topography dependence in western China (Figs. 5b-d). The SCORs are high, at 0.96, 0.95, and 0.95 for RegCM-CLM, RegCMCLM-CN, and RegCM-CLM-CN-DV, respectively (Table 2). However, in all three simulations, a cold bias 
(a) Tree, MODIS, \%

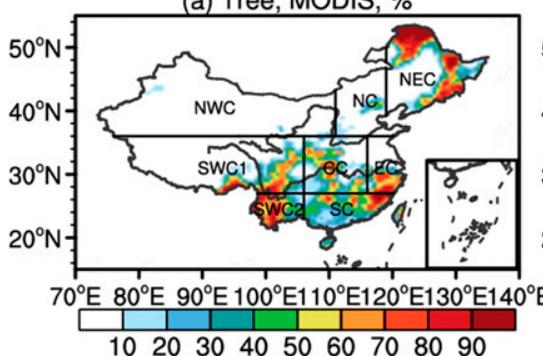

(d) Grass, MODIS, \%

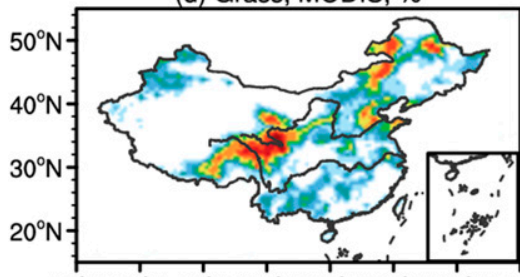

$70^{\circ} \mathrm{E} 80^{\circ} \mathrm{E} 90^{\circ} \mathrm{E} 100^{\circ} \mathrm{E} 110^{\circ} \mathrm{E} 120^{\circ} \mathrm{E} 130^{\circ} \mathrm{E} 140^{\circ} \mathrm{E}$ $10203040506070 \quad 8090$

(g) Crop, MODIS, \%

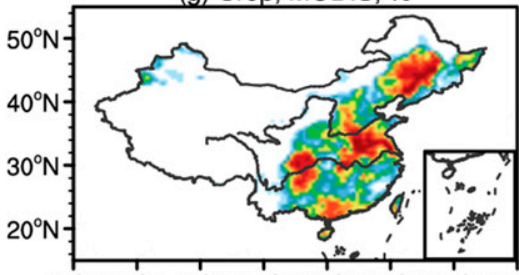

$70^{\circ} \mathrm{E} 80^{\circ} \mathrm{E} 90^{\circ} \mathrm{E} 100^{\circ} \mathrm{E} 110^{\circ} \mathrm{E} 120^{\circ} \mathrm{E} 130^{\circ} \mathrm{E} 140^{\circ} \mathrm{E}$ $\begin{array}{lllllllll}10 & 20 & 30 & 40 & 50 & 60 & 70 & 80 & 90\end{array}$ (j) Bare Soil, MODIS, \%

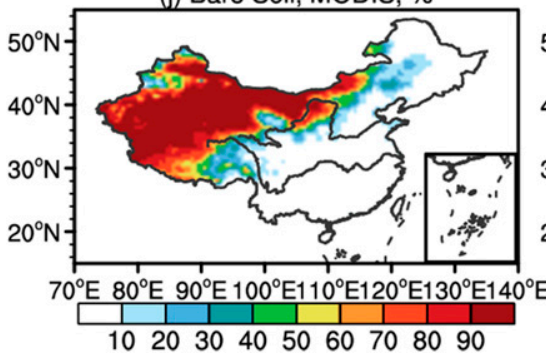

(b) Tree, RegCM-CLM-CN-DV, \%

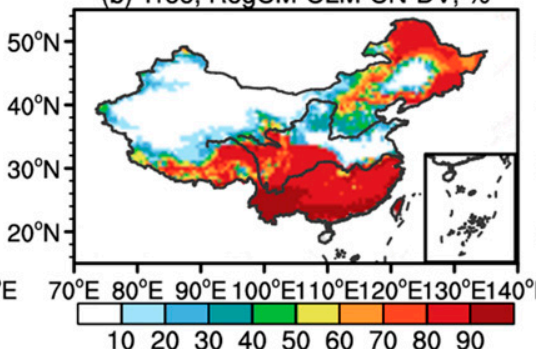

(e) Grass, RegCM-CLM-CN-DV, \%

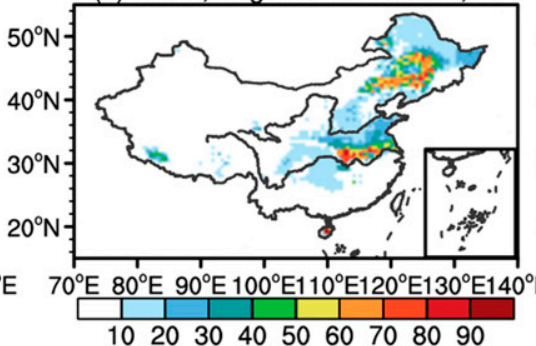

(h) Crop, RegCM-CLM-CN-DV, \%

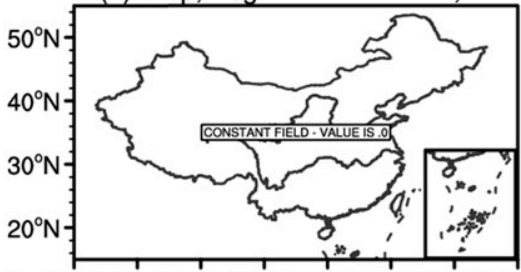

$70^{\circ} \mathrm{E} 80^{\circ} \mathrm{E} 90^{\circ} \mathrm{E} 100^{\circ} \mathrm{E} 110^{\circ} \mathrm{E} 120^{\circ} \mathrm{E} 130^{\circ} \mathrm{E} 140^{\circ} \mathrm{E}$

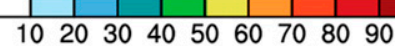

(k) Bare Soil, RegCM-CLM-CN-DV, \%

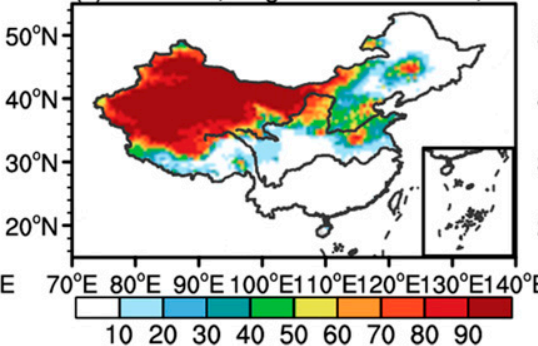

(c) Tree diff., RegCM-CLM-CN-DV, \%

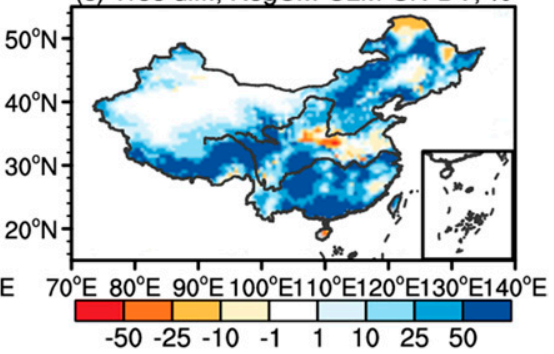

(f) Grass diff., RegCM-CLM-CN-DV, \%

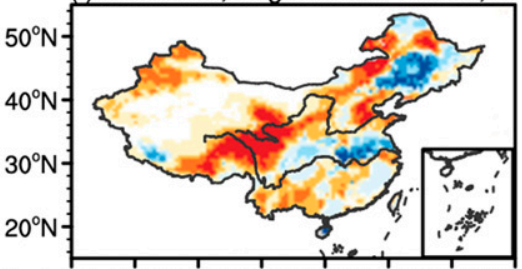

$70^{\circ} \mathrm{E} 80^{\circ} \mathrm{E} 90^{\circ} \mathrm{E} 100^{\circ} \mathrm{E} 110^{\circ} \mathrm{E} 120^{\circ} \mathrm{E} 130^{\circ} \mathrm{E} 140^{\circ} \mathrm{E}$

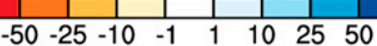

(i) Crop diff., RegCM-CLM-CN-DV, \%

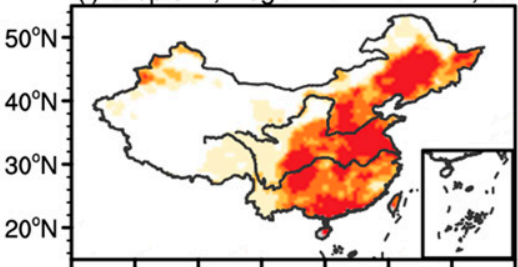

$70^{\circ} \mathrm{E} 80^{\circ} \mathrm{E} 90^{\circ} \mathrm{E} 100^{\circ} \mathrm{E} 110^{\circ} \mathrm{E} 120^{\circ} \mathrm{E} 130^{\circ} \mathrm{E} 140^{\circ} \mathrm{E}$

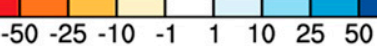

(I) Bare Soil diff., RegCM-CLM-CN-DV, \%

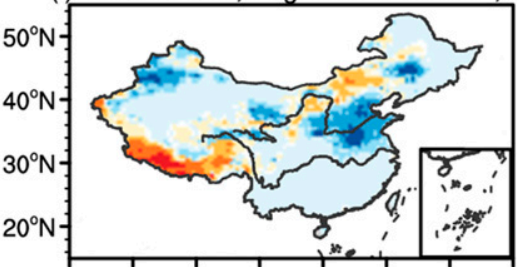

$70^{\circ} \mathrm{E} 80^{\circ} \mathrm{E} 90^{\circ} \mathrm{E} 100^{\circ} \mathrm{E} 110^{\circ} \mathrm{E} 120^{\circ} \mathrm{E} 130^{\circ} \mathrm{E} 140^{\circ} \mathrm{E}$

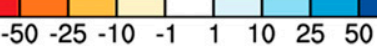

FIG. 2. Averaged fractional coverage (\%) of (a),(b) tree, (d),(e) grasses, (g),(h) crop, and (j),(k) bare soil from the MODIS-derived dataset and simulated by RegCM-CLM-CN-DV over 1990-2009, and (c),(f),(i),(l) the respective differences between the two. Eight subregions of China are shown in Fig. 2a.

can also be found in most of China except the northeast and northwest, and temperature is underestimated by more than $5^{\circ} \mathrm{C}$ over the Tibetan Plateau and southwest China (Figs. 5e-g).

Climate in China is strongly influenced by the East Asia monsoon. Most areas are dry in winter (DJF), especially in the north where winter precipitation totals less than $25 \mathrm{~mm}$; a maxima of DJF total precipitation over $250 \mathrm{~mm}$ can be found in the southeast (Fig. 5h). The simulations in general capture the observed precipitation pattern with an increasing gradient from the northwest to southeast, but precipitation is overestimated in north China and underestimated in southeast China (Figs. 5i-n). The wet biases can be up to $100 \%$ or more in north China and the dry bias in southeast China is mainly in the range of $\sim-75 \%$ to $-50 \%$. Note that the large magnitude of the relative bias in the arid north China is partly due to the small amount of observed precipitation. The SCORs are $0.32,0.37$, and 0.41 and the RMSEs are 0.8, 0.8, and $0.8 \mathrm{~mm} \mathrm{day}^{-1}$, respectively, for the three simulations (Table 2). 

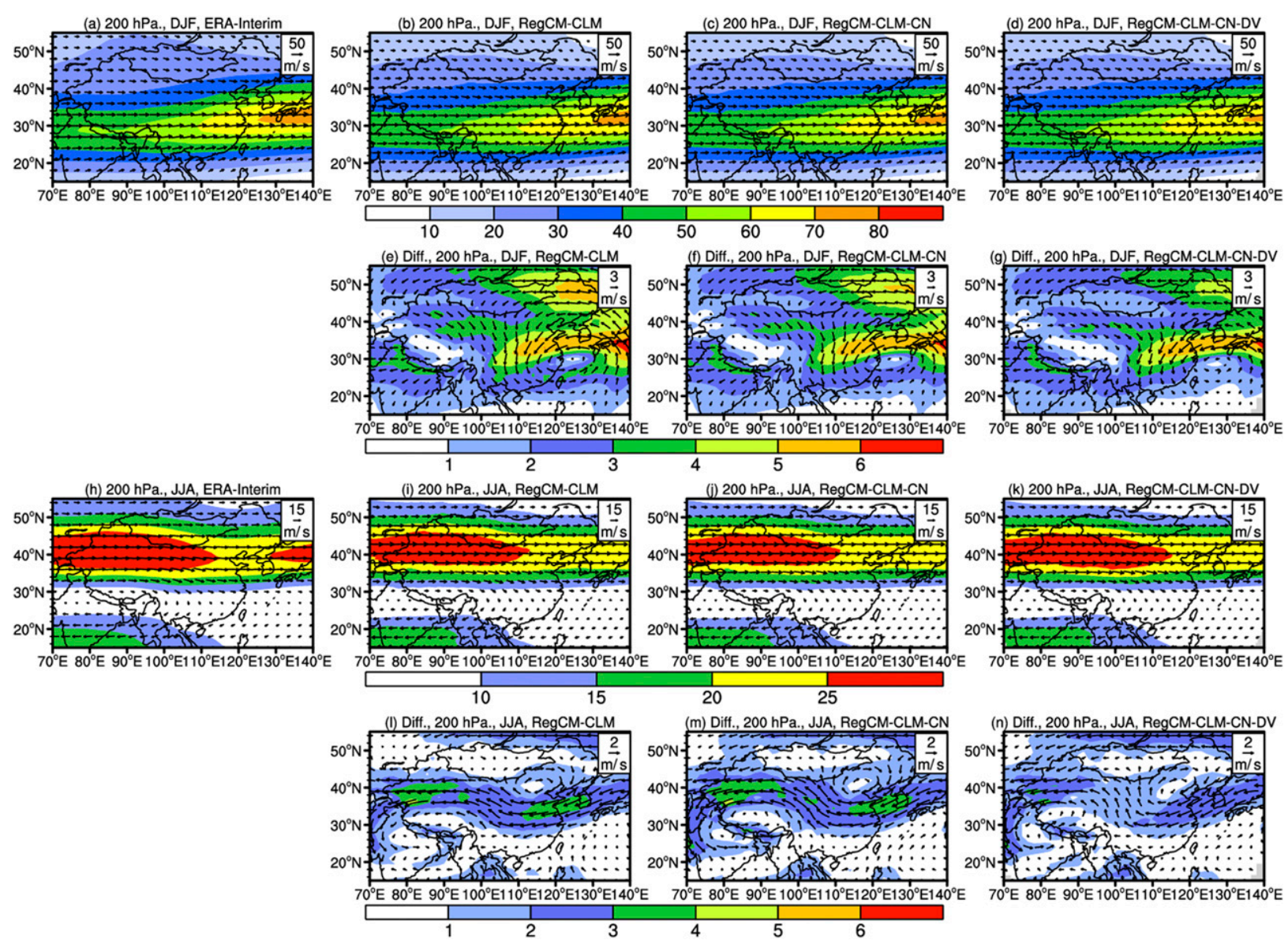

FIG. 3. The 200-hPa wind field (in $\mathrm{m} \mathrm{s}^{-1}$ ) in (a)-(d) DJF and (h)-(k) JJA of 1990-2009 from ERA-Interim reanalysis data and from RegCM-CLM, RegCM-CLM-CN, and RegCM-CLM-CNDV simulations, and (e)-(g) and (l)-(n) the model biases (model minus reanalysis data).

Although the spatial patterns of temperature and precipitation are similar among the three models, substantial differences emerge. Relative to RegCMCLM, RegCM-CLM-CN produces lower temperature and slightly more precipitation over south China, consistent with the LAI difference (Figs. 1i,m). Greater LAI in the model with CN reflects a denser simulated plant canopy than what is prescribed over this area in RegCM-CLM. This enhances the cold biases found in RegCM-CLM, as evaporative cooling is still a significant component of the surface energy budget in winter over south China. In RegCM-CLM-CN-DV (relative to RegCM-CLM), the spatial patterns of temperature difference generally follow those of the surface albedo difference, that is, a colder temperature can be found in the areas where the surface albedo is higher, and vice versa (Figs. 1f,j). The higher surface albedo in northwest and north China is primarily caused by the overestimation of bare soil and underestimation of grasses (Figs. 2f,l, Table 1). In addition, RegCMCLM-CN-DV simulates less precipitation and lower temperature in northern China relative to RegCMCLM (Figs. 1j,n).

\section{2) BOREAL SUMMER}

In JJA, the observed temperature shows a much weaker latitudinal variation and a smaller gradient in eastern China compared to DJF (Fig. 6a). The simulations can well reproduce the observed spatial pattern and the model biases are in general smaller than in DJF (Figs. 6b-g). In contrast to the high degree of model similarity in the biases pattern during DJF, the model biases in JJA differ substantially among the three simulations. RegCM-CLM produces a general warm bias of $1^{\circ}-5^{\circ} \mathrm{C}$ in most parts of China except the Tibetan Plateau, while both the simulations with $\mathrm{CN}$ and with CN-DV produce a general cold bias, except over the northwest. The SCORs are all 0.98 , and the RMSEs are $1.7^{\circ}, 1.6^{\circ}$, and $1.6^{\circ} \mathrm{C}$ for RegCM-CLM, 

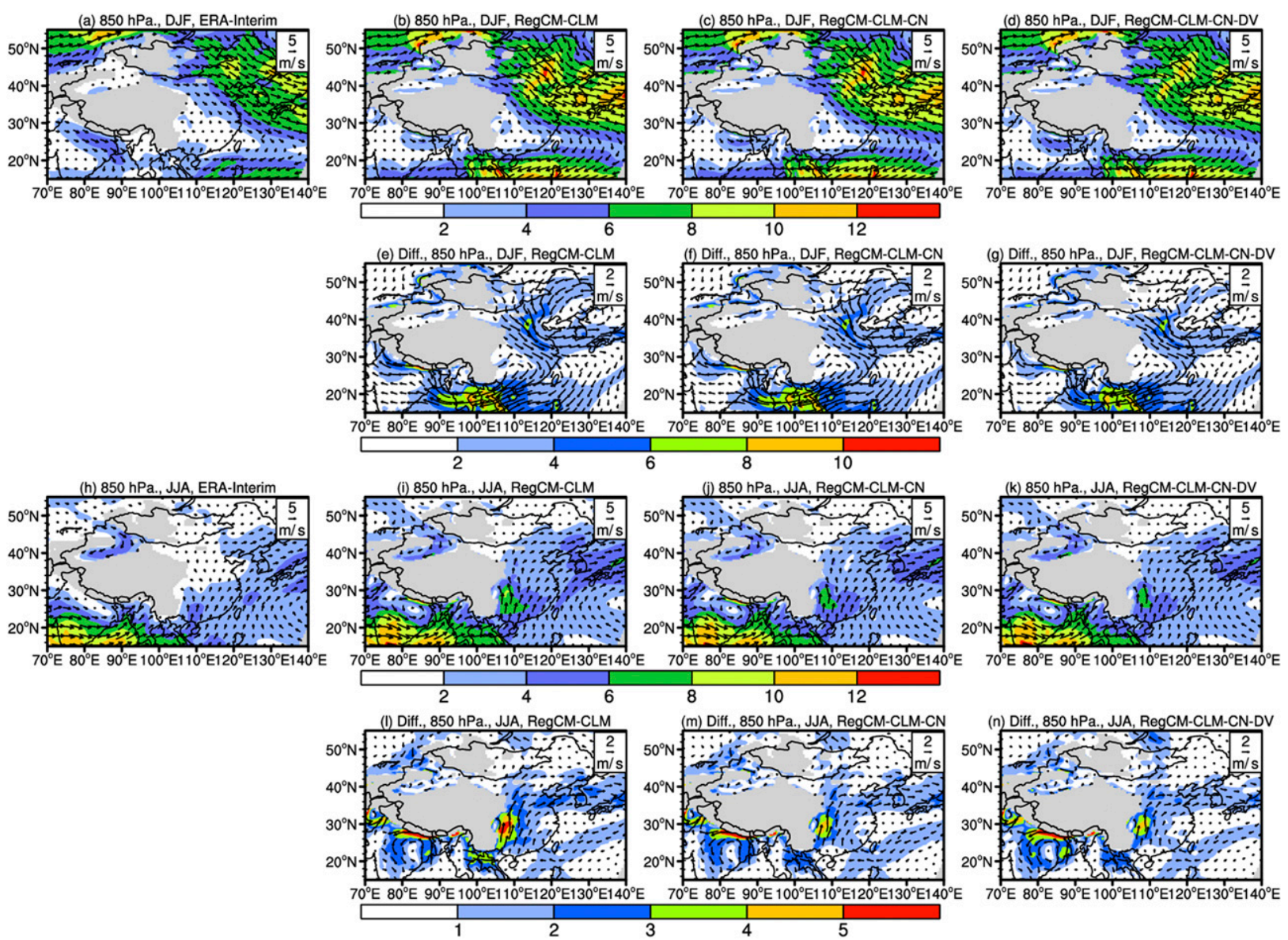

FIG. 4. As in Fig. 3, but for $850 \mathrm{hPa}$. Gray shading indicates areas with elevation higher than $1500 \mathrm{~m}$.

RegCM-CLM-CN, and RegCM-CLM-CN-DV, respectively (Table 2).

JJA is the rainy season in China, during which precipitation is greater than $500 \mathrm{~mm}$ in the south and decreases toward the north and northwest (Fig. 6h). This spatial pattern is in general well captured by the simulations, with a dominant dry bias in northwest China, little difference in south China, and a wet bias in other regions. The SCORs between the model simulations and observation are $0.70,0.73$, and 0.72 , and the RMSEs are 2.4, 2.4, and $2.4 \mathrm{~mm} \mathrm{day}^{-1}$, for RegCM-CLM, RegCMCLM-CN, and RegCM-CLM-CN-DV, respectively (Table 2).

Relative to RegCM-CLM with prescribed vegetation, RegCM-CLM-CN produces a general cooling effect that coincides with a larger LAI (Figs. 1c,k), and so does the RegCM-CLM-CN-DV (Figs. 1d,1). This cooling effect occurs over most of China despite the lower albedo associated with higher LAI, indicating the importance of evaporative cooling in the wet season and regions; over the arid northwest region, the cooling in RegCM-CLM-CN-DV is more related to a decrease of net radiation (Fig. 7b). Over the wet-dry transition zone in western China, precipitation and precipitable water in RegCM-CLM-CN-DV are substantially lower than in RegCM-CLM (Figs. 1p and 7d), which is likely a result of the nonlocal impact of vegetation since the local differences in LAI and vegetation cover between RegCM-CLM-CN-DV and RegCM-CLM are negligible (Figs. 1d, 2c, and 2f). As pointed out by $\mathrm{Ye}$ and $\mathrm{Wu}$ (1998), the Tibetan Plateau acts as a heat source in summer, and the strong surface heating makes the air stratification very unstable and produces ascending flow. Lower net radiation might weaken the heat source (and thus the ascending flow), which can suppress precipitation. On the other hand, decrease of atmospheric precipitable water may reduce the net radiation through the longwave effects. Diagnosing the cause-effect relationships requires specifically designed experiments that are beyond the scope of this paper and will be pursued in follow-up studies. 
(a) Tmp., DJF, CN05.1

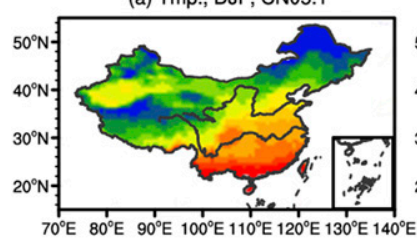

(b) Tmp., DJF, RegCM-CLM

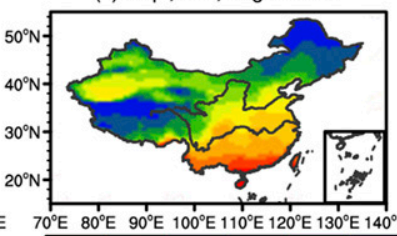

(c) Tmp., DJF, RegCM-CLM-CN

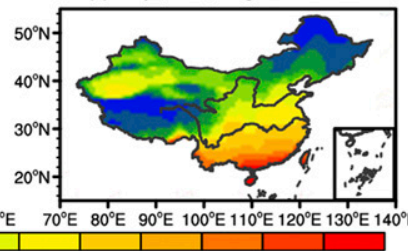

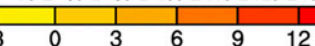

(e) Tmp. diff., DJF, RegCM-CLM

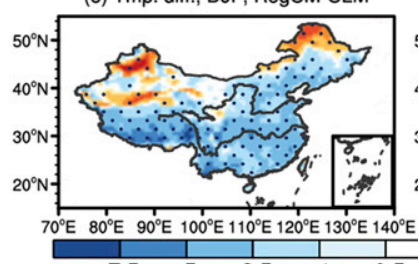

(f) Tmp. diff., DJF, RegCM-CLM-CN

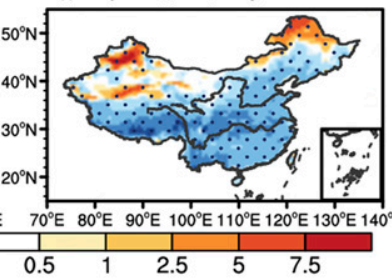

(j) Pre., DJF, RegCM-CLM-CN
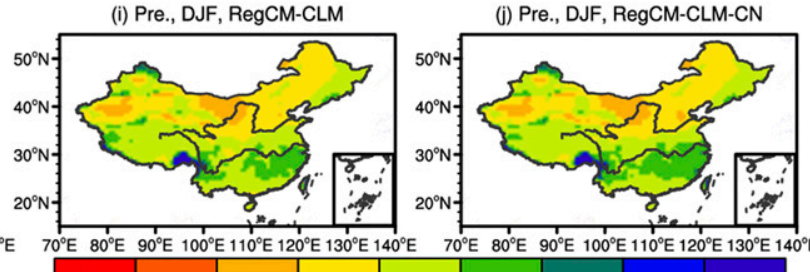

$70^{\circ} \mathrm{E} \quad 80^{\circ} \mathrm{E} \quad 90^{\circ} \mathrm{E} 100^{\circ} \mathrm{E} 110^{\circ} \mathrm{E} 120^{\circ} \mathrm{E} 130^{\circ} \mathrm{E} 140^{\circ}$ $\begin{array}{llll}100 & 150 & 200 & 250\end{array}$

(m) Pre. diff., DJF, RegCM-CLM-CN

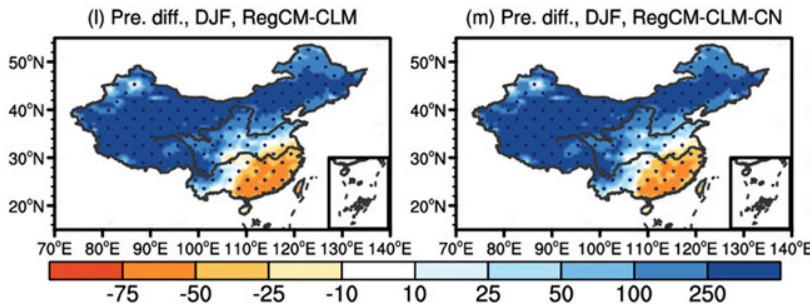

(d) Tmp., DJF, RegCM-CLM-CN-DV

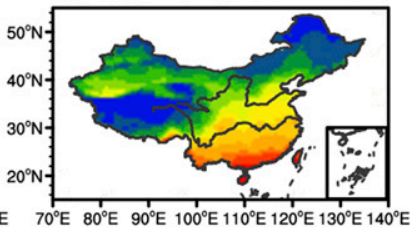

(g) Tmp. diff., DJF, RegCM-CLM-CN-DV

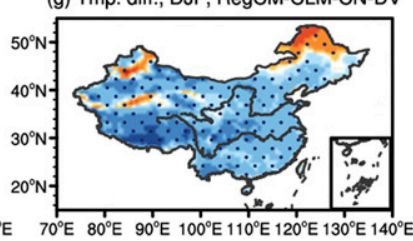

(h) Pre., DJF, CN05.1

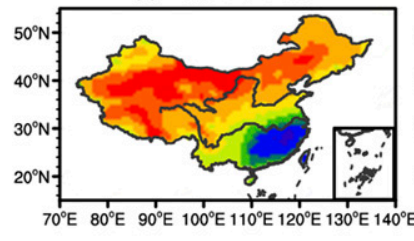

FIG. 5. Observed and simulated (a)-(d) mean temperature $\left({ }^{\circ} \mathrm{C}\right)$ and $(\mathrm{h})-(\mathrm{k})$ precipitation $(\mathrm{mm})$ in DJF of $1990-2009$ over China, and the model biases (model minus observation) of (e)-(g) temperature $\left({ }^{\circ} \mathrm{C}\right)$ and $(1)-(\mathrm{n})$ precipitation $(\%)$ for RegCM-CLM, RegCM-CLM-CN, and RegCM-CLM-CNDV. Shading with black dots indicates biases that are significant at the $95 \%$ confidence level.

\section{d. Annual cycle}

Following $\mathrm{Xu}$ et al. (2015), we divided China into eight subregions: northeast China (NEC), north China (NC), east China (EC), central China (CC), south China (SC), southwest China region 1 (SWC1), southwest China region 2 (SWC2), and northwest China (NWC) (shown in Fig. 2a). Annual cycle of monthly mean temperature over the entirety of China and its eight subregions from observations and the three simulations as well as the model biases are presented in Fig. 8. The observed temperatures show distinct seasonal variations in all regions, with a minimum in January and maximum in July. The difference between the coldest and warmest month is the largest in NEC $\left(40.9^{\circ} \mathrm{C}\right)$ and smallest in SWC1 $\left(11.7^{\circ} \mathrm{C}\right)$. The RegCM simulations capture the annual cycle well, with the TCORs all above 0.96 .
Specifically, the model generally performs better in warm months (from April to September) than cold months (from October to March), with the model bias mostly in the range of $-3.2^{\circ}$ to $2.5^{\circ} \mathrm{C}$ in warm months and $-6.3^{\circ}$ to $2.2^{\circ} \mathrm{C}$ in cold months. Among the three simulations, the performance is better in RegCM-CLM and RegCM-CLM-CN, with TCORs all greater than 0.98 and biases ranging from $-6.2^{\circ}$ to $2.5^{\circ} \mathrm{C}$; RegCMCLM-CN-DV shows a cold bias in all subregions especially in winter months over NC, SWC2, and NWC. In SWC2, the cold bias in RegCM-CLM-CN-DV reaches $-6.3^{\circ} \mathrm{C}$, which is more substantial than in the other two simulations as a result of biases from the climate model and the vegetation model reinforcing each other, as elaborated in Wang et al. (2016).

The observed precipitation reaches a maximum in July in NEC, NC, CC, SWC1, SWC2, NWC, and 
TABLE 2. Spatial correlation coefficient (SCOR) and root-mean-square error (RMSE) between observations and the RegCM-CLM, RegCM-CLM-CN, and RegCM-CLM-CN-DV simulations, for temperature and precipitation annual (ANN) and seasonal (DJF and JJA) averages. The SCORs are all significant at the $95 \%$ confidence level.

\begin{tabular}{|c|c|c|c|c|}
\hline & \multicolumn{2}{|c|}{ SCOR } & \multicolumn{2}{|c|}{ RMSE } \\
\hline & Temperature & Precipitation & Temperature $\left({ }^{\circ} \mathrm{C}\right)$ & Precipitation $\left(\mathrm{mm}\right.$ day $\left.^{-1}\right)$ \\
\hline \multicolumn{5}{|c|}{ RegCM-CLM } \\
\hline ANN & 0.98 & 0.54 & 1.8 & 1.7 \\
\hline DJF & 0.96 & 0.32 & 3.1 & 0.8 \\
\hline JJA & 0.98 & 0.70 & 1.7 & 2.4 \\
\hline \multicolumn{5}{|c|}{ RegCM-CLM-CN } \\
\hline ANN & 0.97 & 0.55 & 2.4 & 1.7 \\
\hline DJF & 0.95 & 0.37 & 3.8 & 0.8 \\
\hline JJA & 0.98 & 0.73 & 1.6 & 2.4 \\
\hline \multicolumn{5}{|c|}{ RegCM-CLM-CN-DV } \\
\hline ANN & 0.97 & 0.57 & 2.8 & 1.7 \\
\hline DJF & 0.95 & 0.41 & 4.2 & 0.8 \\
\hline JJA & 0.98 & 0.72 & 1.6 & 2.4 \\
\hline
\end{tabular}

all-China on average, but for EC and SC, precipitation peaks in June as a result of the summer monsoon's progression and retreat (Fig. 9). The simulations capture the observed seasonal evolution and peaks in most regions, including NEC, NC, EC, SC, SWC1, SWC2, and NWC. However, for CC, precipitation in the model peaks in June instead of July; and for SC, the model simulates a precipitation peak in August in addition to the observed peak in June. The TCORs between the simulations and observation are typically in the range of 0.92-0.99, with the exception of SWC1 in RegCMCLM-CN-DV (0.91). The magnitude of precipitation biases is generally small for EC, CC, and SC, mostly less than $60 \%$. Compared to the observation, precipitation is significantly overestimated for NEC, NC, SWC1, SWC2, NWC, and the all-China average, and is underestimated for SC, especially in the cold months. In most regions, the performances of the model with different vegetation treatments are similar to each other; RegCM-CLM-CN-DV performs better than the other two in NWC, with smaller wet biases in all months.

\section{e. Climate extremes}

To illustrate the model performance in simulating the climate extremes, we selected three temperaturerelated indices, including summer days (annual total number of days with maximum temperature exceeding $\left.25^{\circ} \mathrm{C}, \mathrm{SU}\right)$, warmest day temperature (maximum value of daily maximum temperature, TXx), coldest night temperature (minimum value of daily minimum temperature, $\mathrm{TNn}$ ), and three precipitation-related indices including the maximum number of consecutive dry days (CDD), the maximum consecutive 5-day precipitation (RX5day), and extreme precipitation amount (R95P) proposed by the Expert Team on Climate Change Detection and Indices (ETCCDI) (Frich et al. 2002; Zhang et al. 2011). The temperature-related extremes are shown in Fig. 10, and the precipitation-related extremes are shown in Fig. 11.

The spatial distribution of SU, TXx, and TNn in observation can be well captured by RegCM-CLM, RegCM-CLM-CN, and RegCM-CLM-CN-DV with all SCOR values above 0.90 (Table 3 ). Because of the cold biases of the model, the simulated SU is lower than observed in most areas of north China (Figs. 10a-d). The magnitude of biases is mostly in the range of 5-25 days in all three simulations. Compared to observations, the simulated TXx shows a warm bias exceeding $2.5^{\circ} \mathrm{C}$ in RegCM-CLM and less than $2.5^{\circ} \mathrm{C}$ in the other two simulations in most areas except the Tibetan Plateau (Figs. 10f-h). The observed pattern of TNn is similar to that of the mean temperature in DJF, but with a greater latitudinal gradient from below $-35^{\circ} \mathrm{C}$ in the north to over $10^{\circ} \mathrm{C}$ in the south (Fig. 10i). A general cold bias can be found in south China and the Tibetan Plateau, and it becomes stronger with the addition of $\mathrm{CN}$ or DV model (Figs. 10j-1). In RegCM-CLM-CN-DV, the magnitude of cold biases in most areas exceeds $5^{\circ} \mathrm{C}$. The problem of enhanced model biases when two models are coupled has been elaborated with great detail in Wang et al. (2016). Simply put, the RegCM-CLM model has a large cold bias over most areas of the Tibetan Plateau and south China; as vegetation in RegCM-CLM-CN-DV is allowed to respond to this biased climate and feedback to the climate, model biases feed on each other and grow larger. 
(a) Tmp., JJA, CN05.1

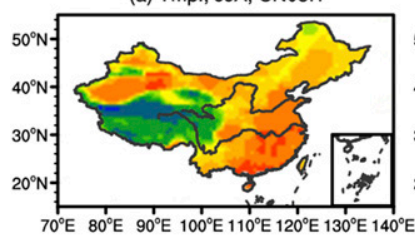

(b) Tmp., JJA, RegCM-CLM

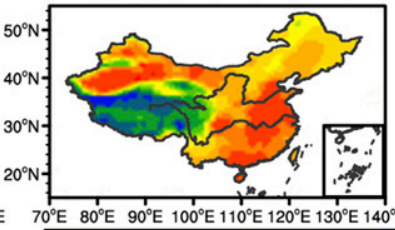

(c) Tmp., JJA, RegCM-CLM-CN

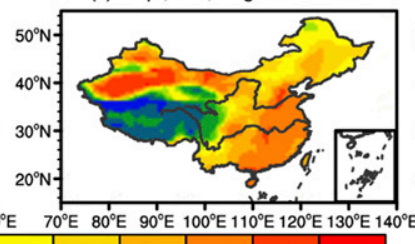

f) Tmp. diff., JJA, RegCM-CLM-CN
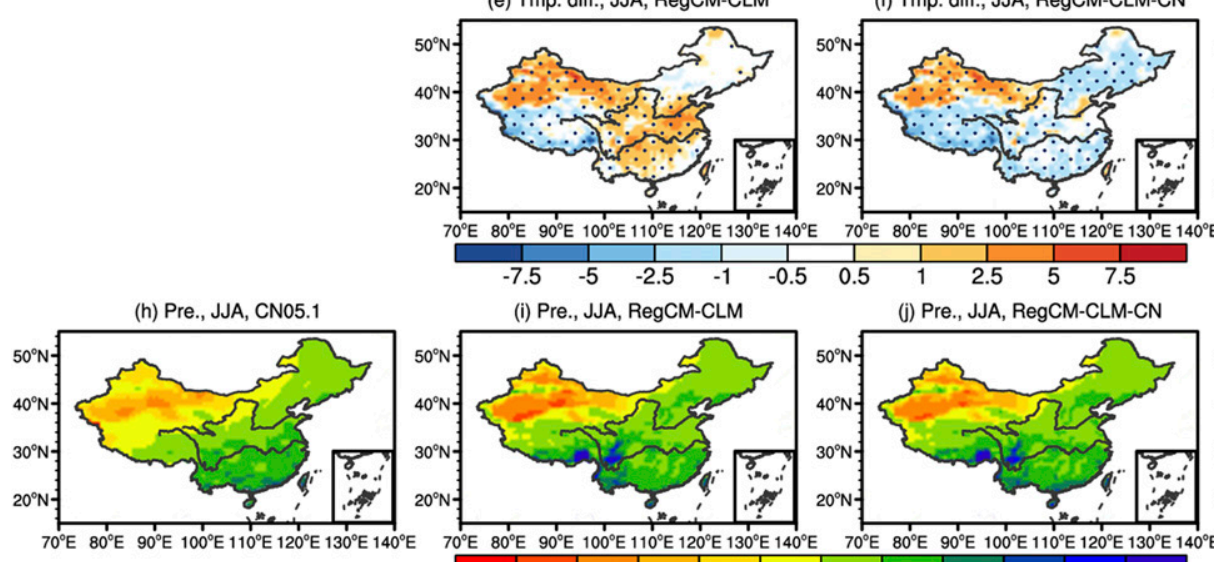

(i) Pre., JJA, RegCM-CLM
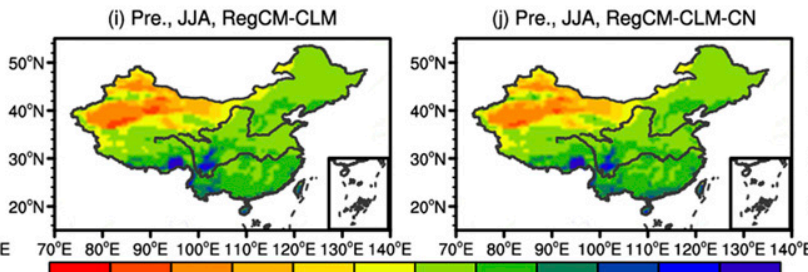

(j) Pre., JJA, RegCM-CLM-CN

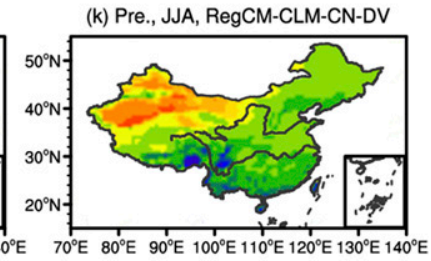

(n) Pre. diff., JJA, RegCM-CLM-CN-DV
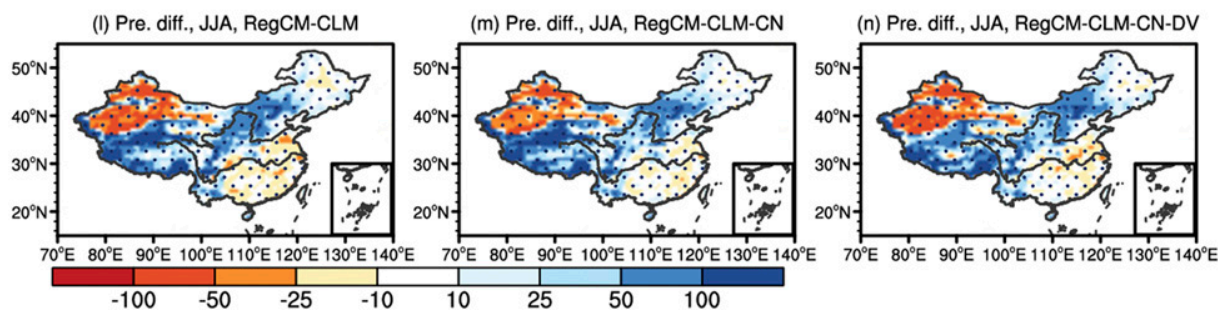

FIG. 6. As in Fig. 5, but for JJA.

As an indicator of drought, more than 210 days of CDD is observed over northwestern China, an arid or semiarid region; in south China, CDD is mostly less than 25 days (Fig. 11a). The performance is similar among the three simulations, with an overestimation over part of the northwest China and south China and underestimation elsewhere (Figs. 11b-d). The SCORs are 0.37, 0.40, and 0.53 and RMSEs are 71, 72, and 66 days for RegCM-CLM, RegCM-CLM-CN, and RegCMCLM-CN-DV, respectively (Table 3).

The model can reproduce the observed decreasing gradient from the southeast to northwest of RX5day and R95P, with relatively high SCORs (exceeding 0.7 and 0.6 for RX5day and R95P, respectively) for all three simulations (Figs. 11e-1, Table 3). However, a dominant wet bias with values more than $50 \%$ from northeast toward southwest can be found in all of the three simulations for RX5day (Figs. 11f-h), and similar wet biases are found for R95P with magnitude exceeding $100 \%$ over most of north and west China (Figs. 11j-1). The differences of CDD, RX5day, and R95P in most areas with the values greater than $25 \%$ are significant at the $95 \%$ confidence level.

\section{f. Interannual variability}

Figure 12 shows the interannual variability of temperature anomalies (relative to the 1990-2009 climatology) averaged over the entirety of China and its eight subregions, based on observational data and simulations. All three simulations capture the observed interannual variability in most regions; the TCORs are greater than 0.60, with the exception of NC in RegCMCLM (0.48, Table 4). When dynamic vegetation is included as in RegCM-CLM-CN-DV, the model performs better than the other two simulations over most regions (except NEC, SC, and NWC), with TCORs greater than 0.70 in all regions. An increasing trend is observed in all regions, and is the most significant $\left[\right.$ at $0.7^{\circ} \mathrm{C}(10 \mathrm{yr})^{-1}$ ] in SWC2. However, the trends simulated by RegCM-CLM are $0.1^{\circ} \mathrm{C}(10 \mathrm{yr})^{-1}$ in most (six) subregions, much lower 
(a) Net Rad. diff., JJA, RegCM-CLM-CN

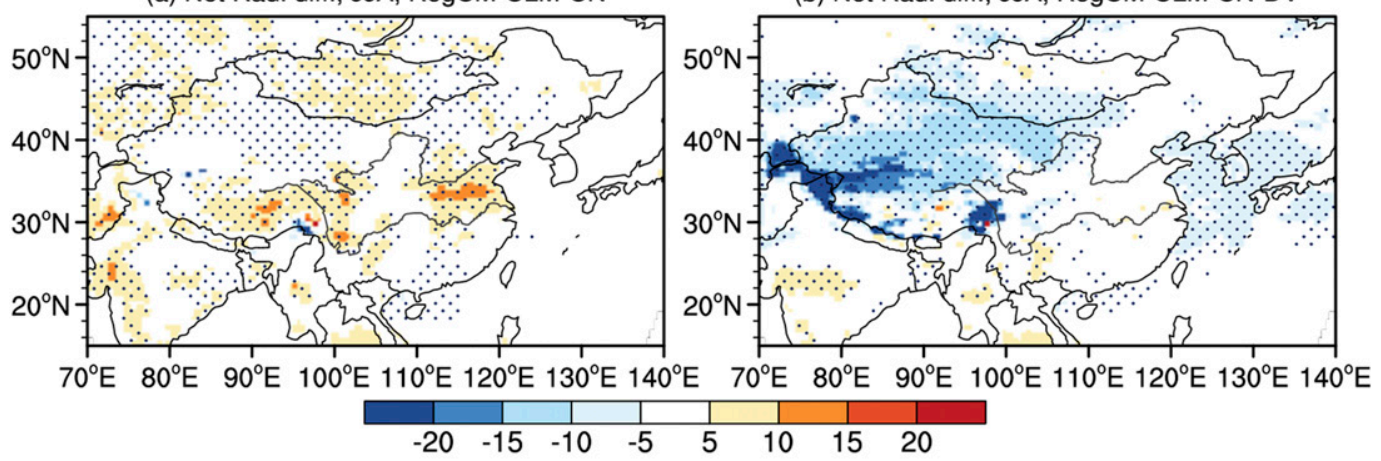

(c) Water Vapor flux diff., JJA, RegCM-CLM-CN

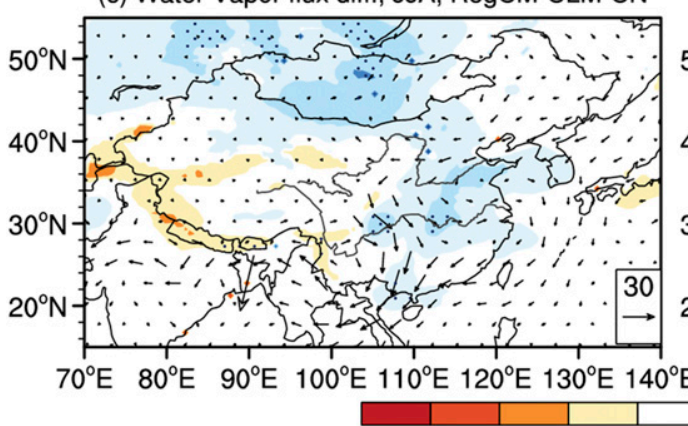

$\begin{array}{llllllll}-10 & -5 & -2.5 & -1 & 1 & 2.5 & 5 & 10\end{array}$ (d) Water Vapor flux diff., JJA, RegCM-CLM-CN-DV

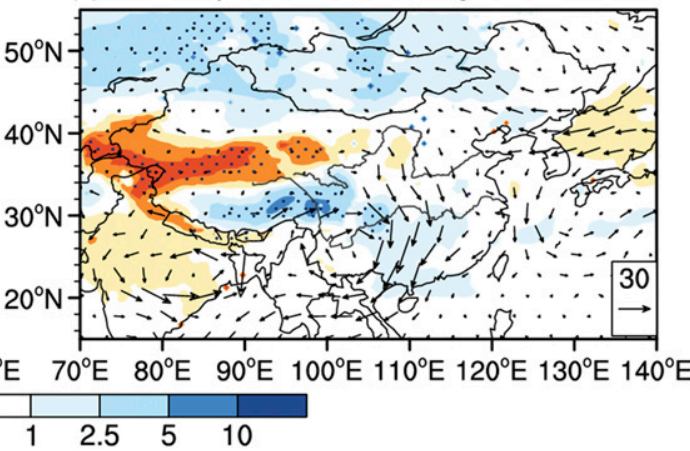

FIG. 7. Difference in (a),(b) net radiation $\left(\mathrm{W} \mathrm{m}^{-2}\right)$ and (c),(d) integrated water vapor flux (vector, $\mathrm{kg} \mathrm{m}^{-1} \mathrm{~s}^{-1}$ ) and precipitable water (shaded, \%) in JJA, between RegCM-CLM-CN and RegCM-CLM, and between RegCM-CLM-CN-DV and RegCM-CLM. Black dots indicate areas where the differences are significant at the $95 \%$ confidence level.

than observed. Similar results can also be found in RegCM-CLM-CN [trends mostly in the range of $0.1^{\circ}-$ $0.2^{\circ} \mathrm{C}(10 \mathrm{yr})^{-1}$; t the performance is better in RegCMCLM-CN-DV, with most of the trends in the range of $\left.0.3^{\circ}-0.5^{\circ} \mathrm{C}(10 \mathrm{yr})^{-1}\right]$.

The interannual variability of precipitation anomalies averaged over the whole China and most of the eight subregions are well captured by all three simulations (Fig. 13), although the performance for precipitation is not as good as for temperature. The TCORs are in the range of $0.33-0.89,0.37-0.87$, and $0.36-0.86$ in RegCMCLM, RegCM-CLM-CN, and RegCM-CLM-CN-DV, respectively (Table 4). While the simulations do not differ much in their average over China as a whole, strong variations are found in subregions. For example, according to the values of TCOR, RegCM-CLM performs well in NC and China as a whole; RegCM-CLM$\mathrm{CN}$ performs well in $\mathrm{CC}, \mathrm{SC}, \mathrm{SWC} 2, \mathrm{NWC}$; and RegCM-CLM-CN-DV is the best performer for NEC, $\mathrm{EC}$, and SWC1. Significant biases can also be found in some regions. For example, in CC, precipitation anomalies in 1998 were the strongest observed as a result of El Niño, but are negligible based on model simulations regardless of whether carbon-nitrogen dynamics or vegetation dynamics is included in the model.

\section{Summary and discussion}

In this paper, we evaluate the performances of the Regional Climate Model RegCM4.3.4-CLM4.5 with prescribed vegetation coupled with $\mathrm{CN}$ or $\mathrm{CN}-\mathrm{DV}$ over China and its subregions. In general, the model can well reproduce the present-day climate over China. Major biases include a cold bias in winter across most of China, and an overestimation of precipitation in the arid north and an underestimation in the wet south setting up a smaller latitudinal gradient of precipitation. These biases are in line with the previous RegCM versions, as well as many other climate model simulations (Xu et al. 2009; Gao et al. 2017). Among the three simulations with different vegetation treatments, cold biases are the strongest in the model with dynamic vegetation, as a result of the feedback between dynamic vegetation and climate amplifying biases of the component models ( $\mathrm{Yu}$ et al. 2016; Wang et al. 2016; Erfanian et al. 2016). On the other hand, underestimation of precipitation in 
(a) Tmp., China, ${ }^{\circ} \mathrm{C}$

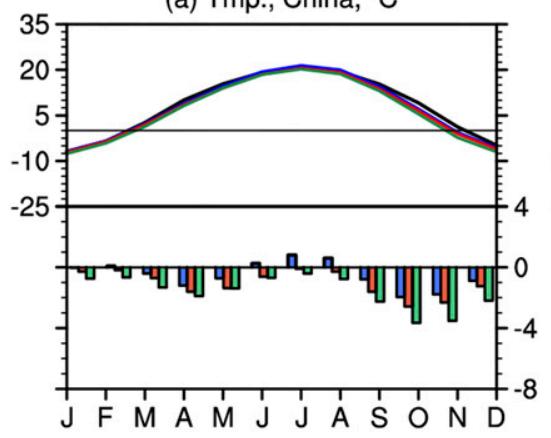

(d) Tmp., East China, ${ }^{\circ} \mathrm{C}$

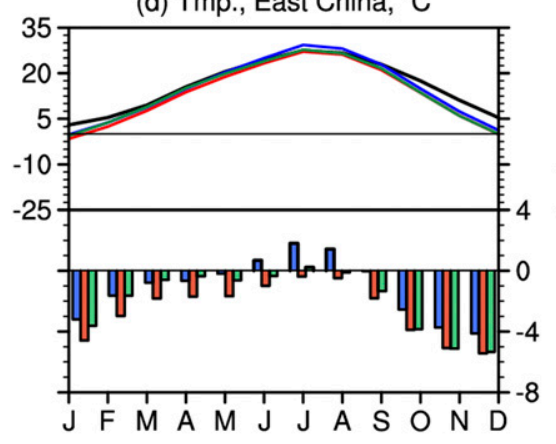

(g) Tmp., Southwest China $1,{ }^{\circ} \mathrm{C}$

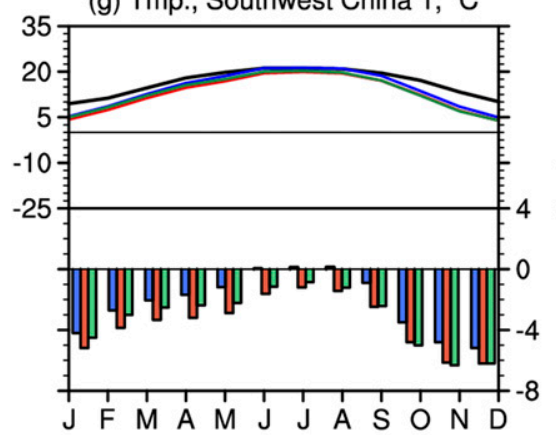

$-\mathrm{CN} 05.1$ (b) Tmp., Northeast China, ${ }^{\circ} \mathrm{C}$

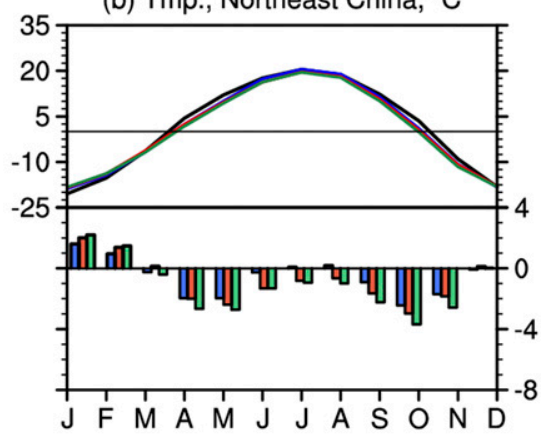

(e) Tmp., Central China, ${ }^{\circ} \mathrm{C}$

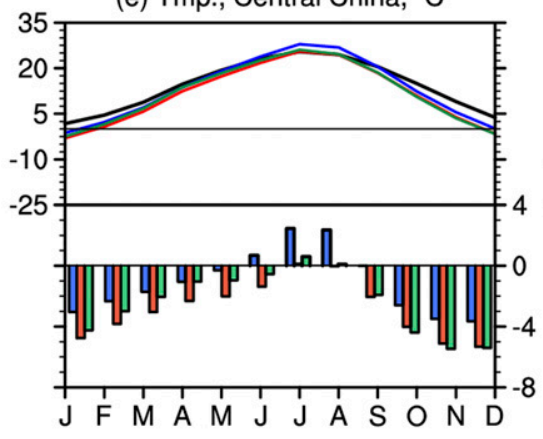

(h) Tmp., Southwest China $2,{ }^{\circ} \mathrm{C}$

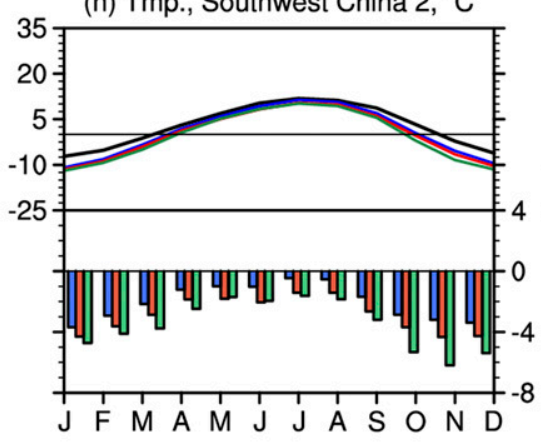

- RegCM-CLM-CN

$\square$ RegCM-CLM-CN (c) Tmp., North China, ${ }^{\circ} \mathrm{C}$

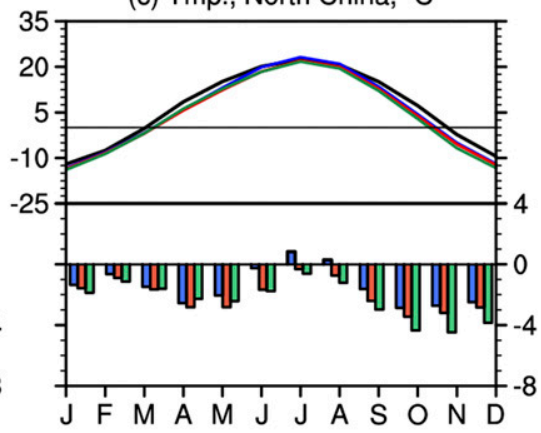

(f) Tmp., South China, ${ }^{\circ} \mathrm{C}$

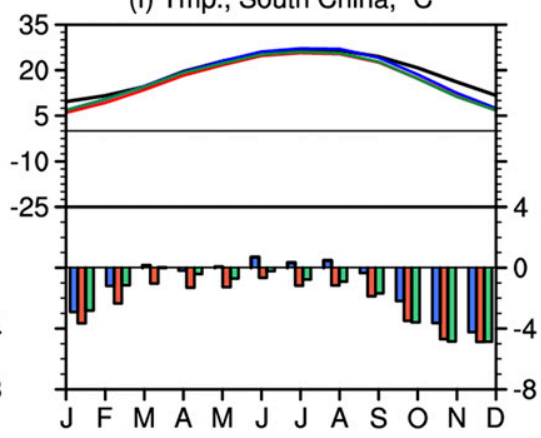

(i) Tmp., Northwest China, ${ }^{\circ} \mathrm{C}$

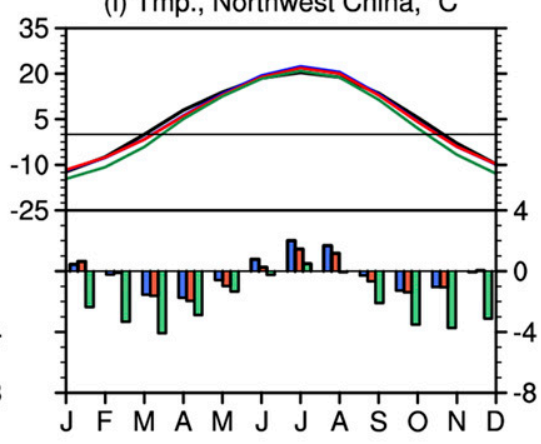

- RegCM-CLM-CN-DV

$\square$ RegCM-CLM-CN-DV

FIG. 8. Annual cycle of temperature (line) and temperature biases (model minus observation, bar) averaged over the entirety of China and its eight subregions (in ${ }^{\circ} \mathrm{C}$ ) (black line: CN05.1, blue line/bar: RegCM-CLM, red line/bar: RegCM-CLM-CN, and green line/bar: RegCM-CLM-CN-DV).

south China is a major deficiency in RegCM model simulations (Gao et al. 2017). This may be related to the model's convective scheme, which needs to be further investigated. Obviously, the added model capacity (of predicting vegetation phenology and vegetation distribution) could not (and is not meant to) correct model biases related to other model parameters. Overall, despite the expected amplification of model biases due to feedback, the differences among the three simulations are much smaller than the model biases.
Still, significant differences can be found among the three simulations. The simulation with $\mathrm{CN}$ overestimates LAI especially in southern China, which through evaporative cooling causes a stronger cold bias than the model with prescribed phenology; the simulation with dynamic vegetation significantly overestimates the fractional coverage of bare soil, needleleaf evergreen boreal trees, and broadleaf deciduous temperate trees, underestimates the fractional coverage of C3 grass, and does not simulate crops. Over regions where tree coverage is overestimated, surface albedo 
(a) Pre., China, $\mathrm{mm} \& \%$

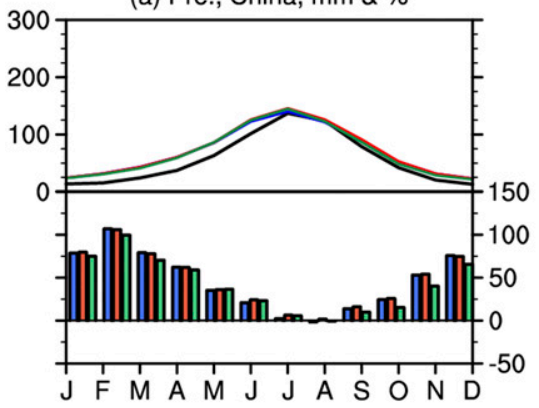

(d) Pre., East China, mm \& \%

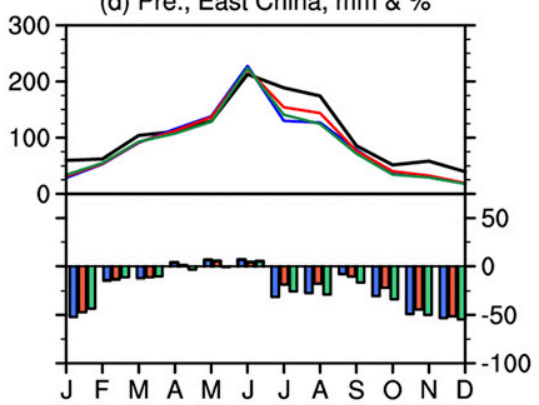

(g) Pre., Southwest China 1, mm \& \%

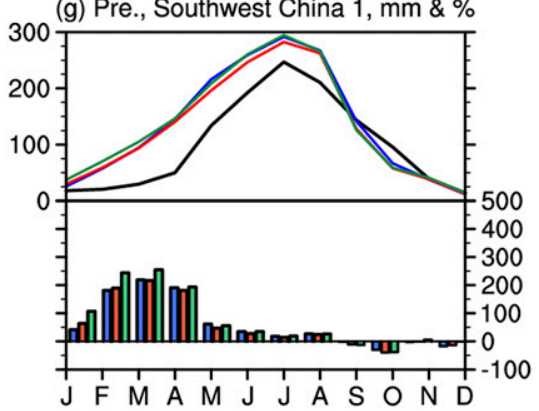

(b) Pre., Northeast China, $\mathrm{mm} \& \%$

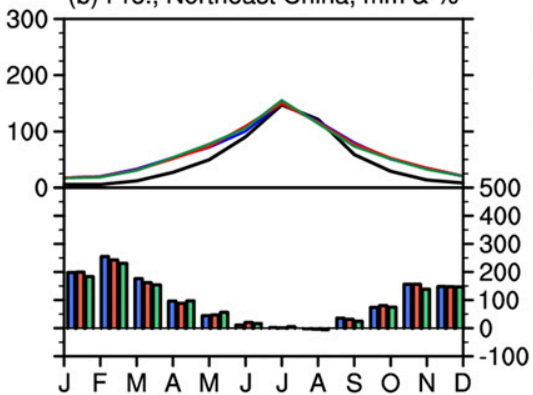

(e) Pre., Central China, mm \& \%

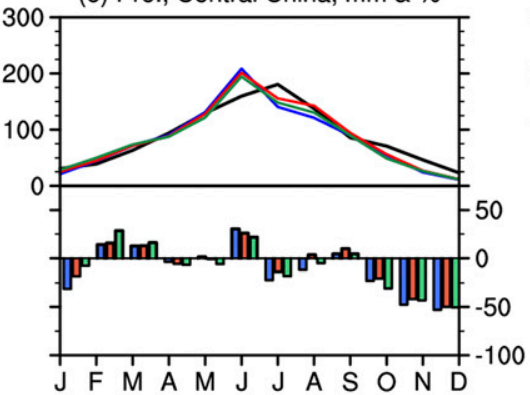

(h) Pre., Southwest China 2, $\mathrm{mm} \& \%$

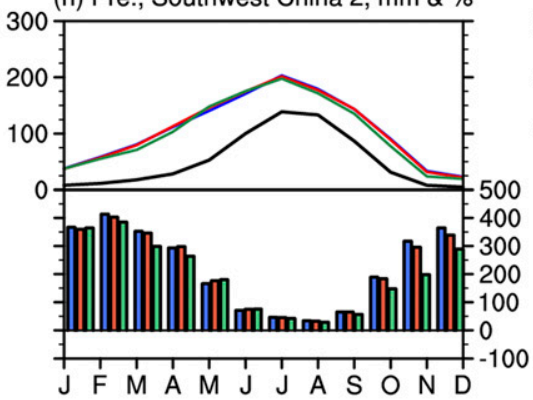

- RegCM-CLM-CN

$\square$ RegCM-CLM-CN (c) Pre., North China, mm \& \%

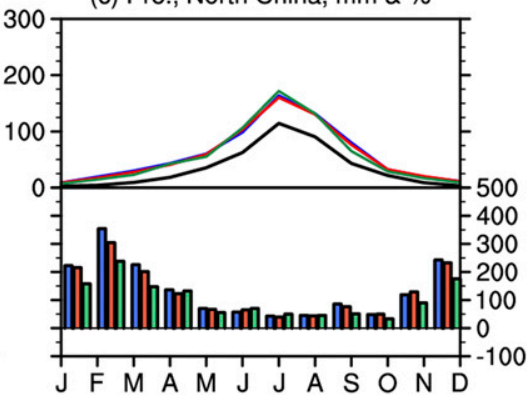

(f) Pre., South China, $m m \& \%$

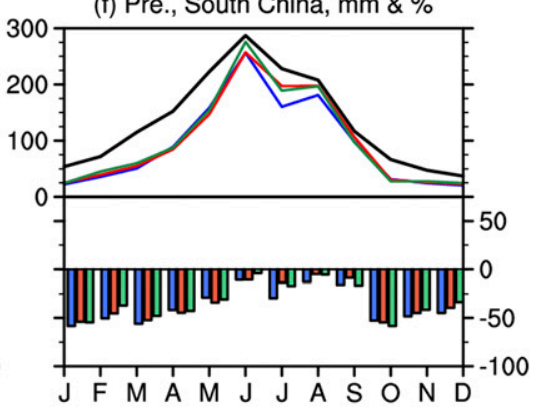

(i) Pre., Northwest China, mm \& \%

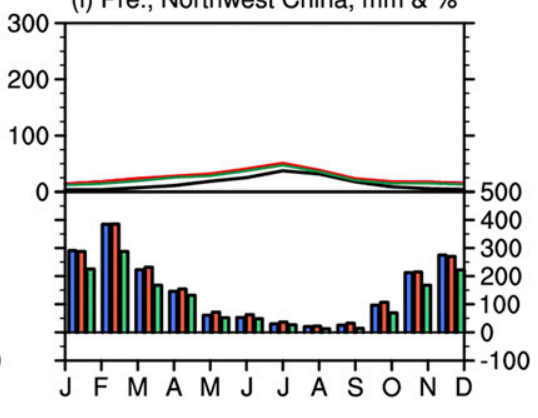

- RegCM-CLM-CN-DV

$\square$ RegCM-CLM-CN-DV

FIG. 9. As in Fig. 8, but for precipitation ( $\mathrm{mm}$ ) and precipitation biases (\%).

is underestimated; elsewhere, surface albedo in RegCM-CLM-CN-DV is overestimated. Overestimation of albedo is the main cause for the enhanced cold bias in winter; in summer, the overestimation of LAI enhances the cold bias in eastern China through evaporative cooling, while a reduced net radiation dominates the cold biases in the west. The reduced net radiation over the Tibetan Plateau might weaken the heat source and hence the ascending flow, which could weaken precipitation. In addition, relative to the simulation with prescribed vegetation, the stronger westerly water vapor flux and less precipitable water may also enhance the underestimation of precipitation over the Tibetan Plateau.
Qualitatively, RegCM-CLM-CN simulates the dayto-day LAI variation in response to meteorological conditions and thus accounts for vegetation feedback to climate at the subseasonal to season time scales, which makes it a more suitable modeling tool than RegCM-CLM for studying land-atmosphere interactions at the subseasonal to interannual time scales, and for attribution studies on seasonal extremes. On a similar note, RegCM-CLM-CN-DV simulates year-to-year variation of vegetation coverage in response to climate and feeds back to the climate at the interannual to decadal and longer time scales, which makes it a more suitable tool for studying the interannual variability of climate and long-term climate changes than both RegCM-CLM-CN 
(a) SU, CN05.1, days

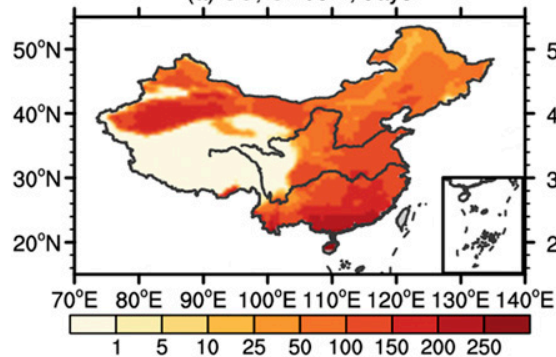

(b )SU diff., RegCM-CLM, days

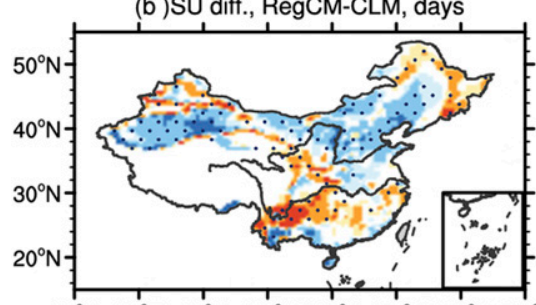

$70^{\circ} \mathrm{E} \quad 80^{\circ} \mathrm{E} \quad 90^{\circ} \mathrm{E} 100^{\circ} \mathrm{E} 110^{\circ} \mathrm{E} 120^{\circ} \mathrm{E} 130^{\circ} \mathrm{E} 140^{\circ} \mathrm{E}$

(c) SU diff., RegCM-CLM-CN, days

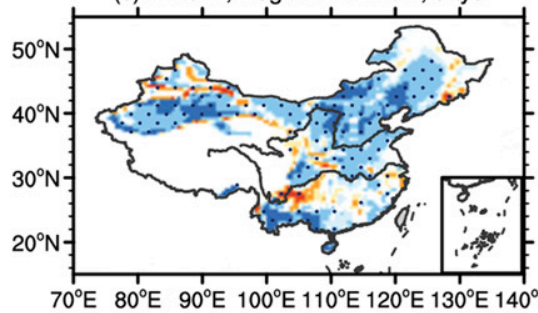

(d) SU diff., RegCM-CLM-CNDV, days

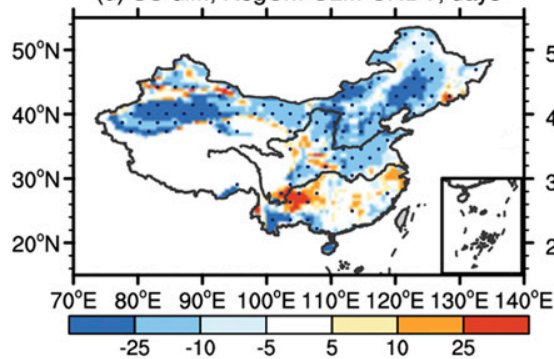

(e) TXx, CN05.1, ${ }^{\circ} \mathrm{C}$

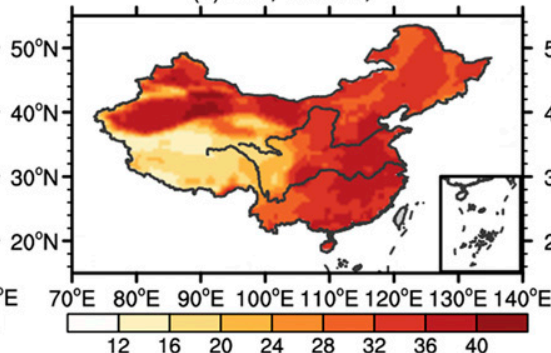

(f) $\mathrm{TXx}$ diff., RegCM-CLM, ${ }^{\circ} \mathrm{C}$

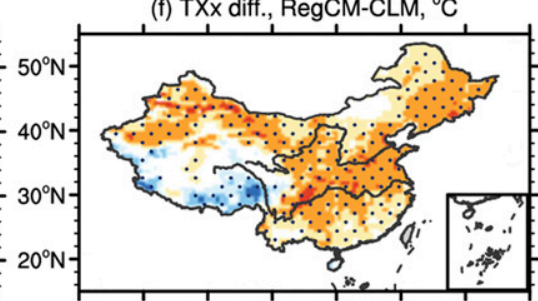

$70^{\circ} \mathrm{E} \quad 80^{\circ} \mathrm{E} \quad 90^{\circ} \mathrm{E} 100^{\circ} \mathrm{E} 110^{\circ} \mathrm{E} 120^{\circ} \mathrm{E} 130^{\circ} \mathrm{E} 140^{\circ} \mathrm{E}$

(g) TXx diff., RegCM-CLM-CN, ${ }^{\circ} \mathrm{C}$

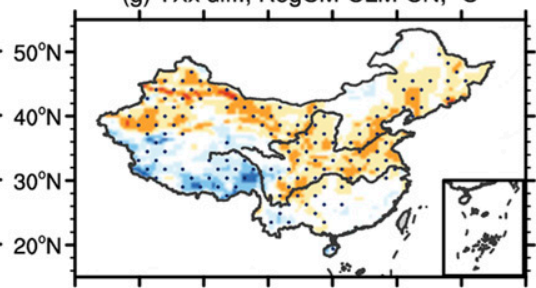

$70^{\circ} \mathrm{E} \quad 80^{\circ} \mathrm{E} 90^{\circ} \mathrm{E} 100^{\circ} \mathrm{E} 110^{\circ} \mathrm{E} 120^{\circ} \mathrm{E} 130^{\circ} \mathrm{E} 140^{\circ}$

(h) TXx diff., RegCM-CLM-CNDV, ${ }^{\circ} \mathrm{C}$

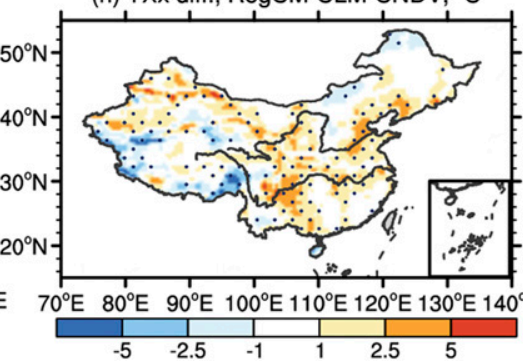

(i) $\mathrm{TNn}, \mathrm{CN} 05.1,{ }^{\circ} \mathrm{C}$

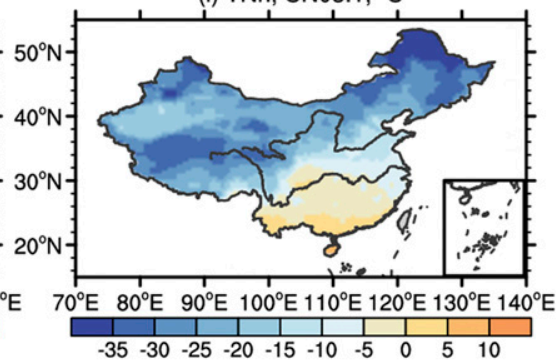

(j) TNn diff., RegCM-CLM, ${ }^{\circ} \mathrm{C}$

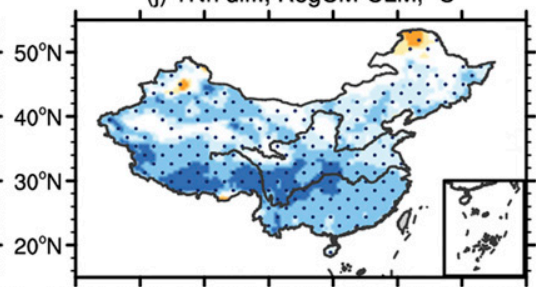

(k) TNn diff., RegCM-CLM-CN, ${ }^{\circ} \mathrm{C}$

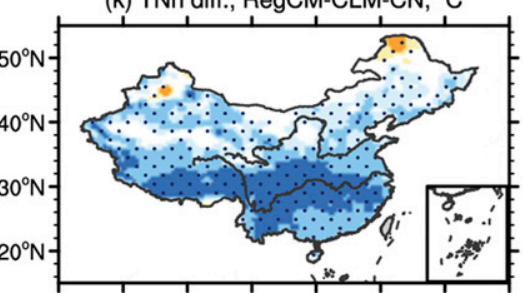

$70^{\circ} \mathrm{E} \quad 80^{\circ} \mathrm{E} \quad 90^{\circ} \mathrm{E} 100^{\circ} \mathrm{E} 110^{\circ} \mathrm{E} 120^{\circ} \mathrm{E} 130^{\circ} \mathrm{E} 140^{\circ} \mathrm{E}$

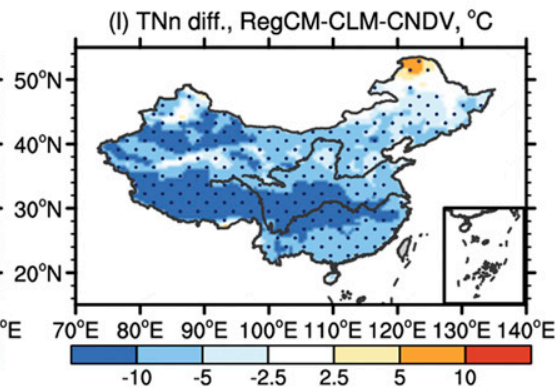

FIG. 10. Observed temperature-related extremes and the model biases (model minus observation): (a)-(d) SU (days), (e)-(h) TXx $\left({ }^{\circ} \mathrm{C}\right)$, and (i)-(l) TNn $\left({ }^{\circ} \mathrm{C}\right)$. Black dots indicate areas where the differences are significant at the $95 \%$ confidence level.

and RegCM-CLM. Indeed, among the three simulations in this study, the RegCM-CLM-CN-DV performs the best in simulating the interannual variability of temperature based on average over the entirety of China and for most of the subregions, and also in simulating the interannual variability of precipitation for some of the subregions including NEC, EC, and SWC1. Quantitatively, the differences in vegetation phenology among the three simulations and the magnitude of the simulated interannual variations of PFT coverage in RegCM-CLM-CN-DV are region dependent and PFT dependent. For example, the interannual variability of vegetation fractional coverage is negligible in wet regions (e.g., the Yangtze River basin) and tends to be much larger in drier regimes (e.g., northern China plain), and grass coverage tends to show larger yearto-year fluctuations than tree coverages. However, overall, the differences between simulations with static and dynamic vegetation representations are generally small for the present-day climate. For shortperiod studies around present day, models with prescribed vegetation distribution should be sufficient, and either satellite phenology or predictive phenology may be chosen depending on the process of interest. For example, when the focus is solely on soil moisture-precipitation feedback (e.g., Mei et al. 2013; 
(a) CDD, CN05.1, days

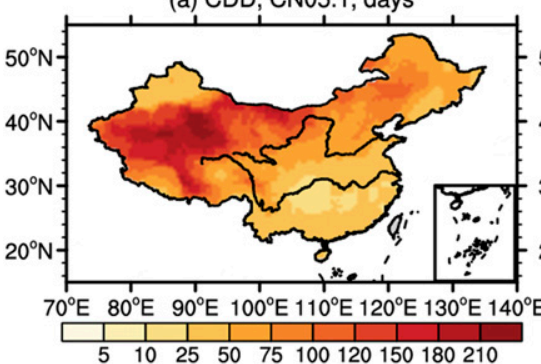

(b) CDD diff., RegCM-CLM, \%

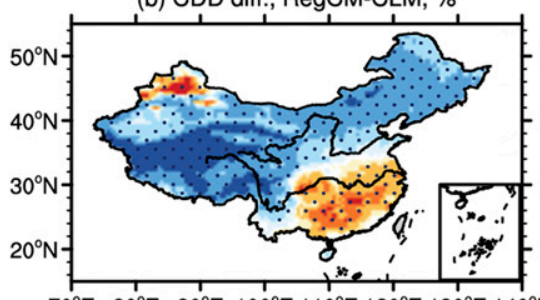

$70^{\circ} \mathrm{E} \quad 80^{\circ} \mathrm{E} \quad 90^{\circ} \mathrm{E} 100^{\circ} \mathrm{E} 110^{\circ} \mathrm{E} 120^{\circ} \mathrm{E} 130^{\circ} \mathrm{E} 140^{\circ} \mathrm{E}$

(c) CDD diff., RegCM-CLM-CN, \%

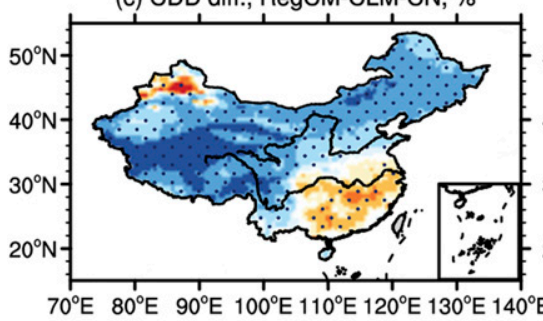

(d) CDD diff., RegCM-CLM-CNDV, \%

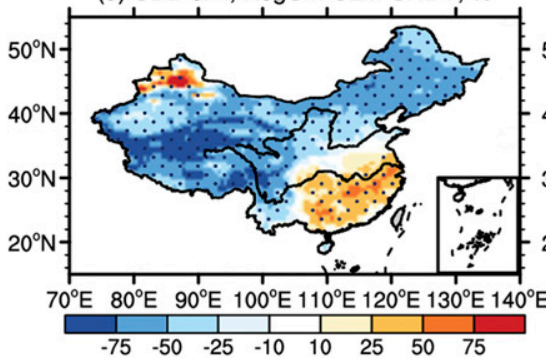

(e) RX5day, CN05.1, mm

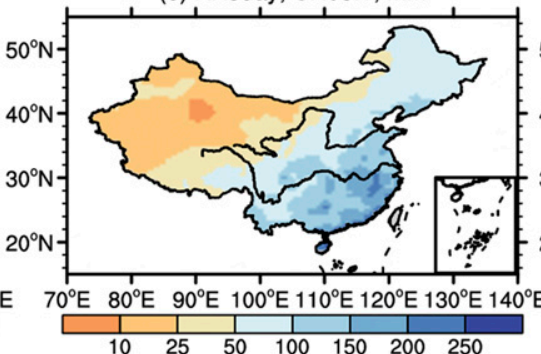

(f) RX5day diff., RegCM-CLM, \%

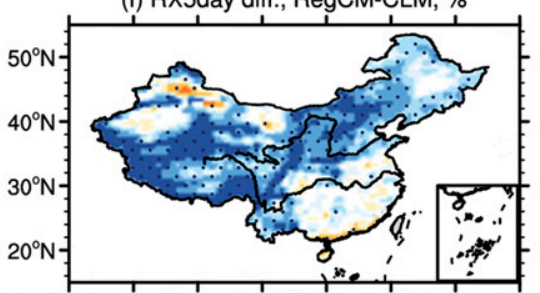

$70^{\circ} \mathrm{E} \quad 80^{\circ} \mathrm{E} \quad 90^{\circ} \mathrm{E} 100^{\circ} \mathrm{E} 110^{\circ} \mathrm{E} 120^{\circ} \mathrm{E} 130^{\circ} \mathrm{E} 140^{\circ} \mathrm{E}$

(g) RX5day diff., RegCM-CLM-CN, \%

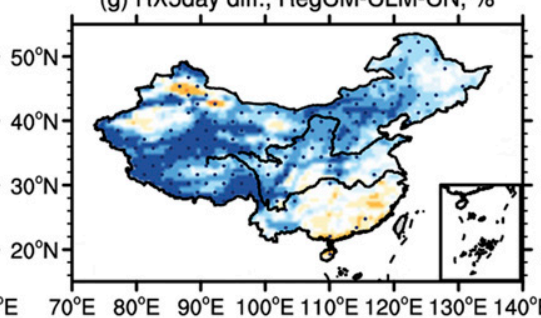

(h) RX5day diff., RegCM-CLM-CNDV, \%

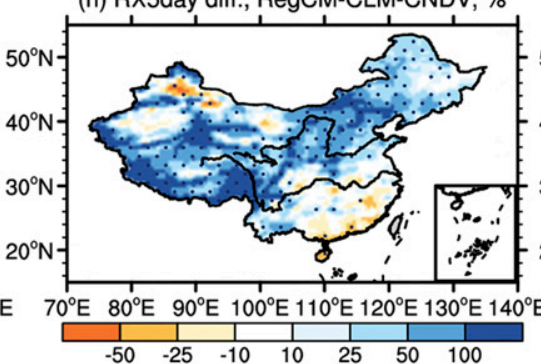

(i) R95P, CN05.1, mm

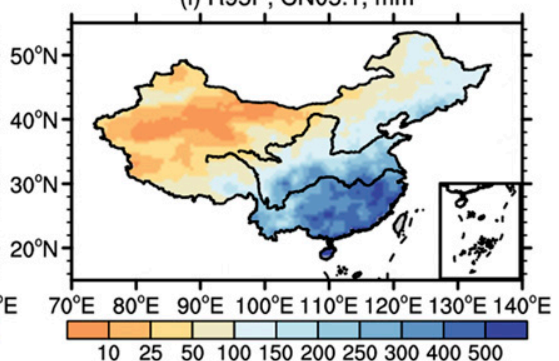

(j) R95P diff., RegCM-CLM, \%

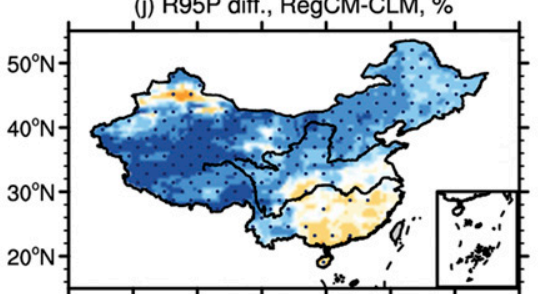

$70^{\circ} \mathrm{E} \quad 80^{\circ} \mathrm{E} 90^{\circ} \mathrm{E} 100^{\circ} \mathrm{E} 110^{\circ} \mathrm{E} 120^{\circ} \mathrm{E} 130^{\circ} \mathrm{E} 140^{\circ} \mathrm{E}$

(k) R95P diff., RegCM-CLM-CN, \%

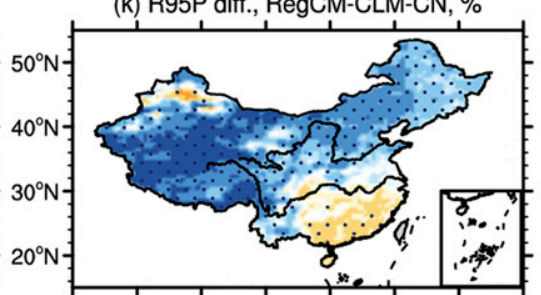

$70^{\circ} \mathrm{E} \quad 80^{\circ} \mathrm{E} \quad 90^{\circ} \mathrm{E} 100^{\circ} \mathrm{E} 110^{\circ} \mathrm{E} 120^{\circ} \mathrm{E} 130^{\circ} \mathrm{E} 140^{\circ} \mathrm{E}$

(I) R95P diff., RegCM-CLM-CNDV, \%

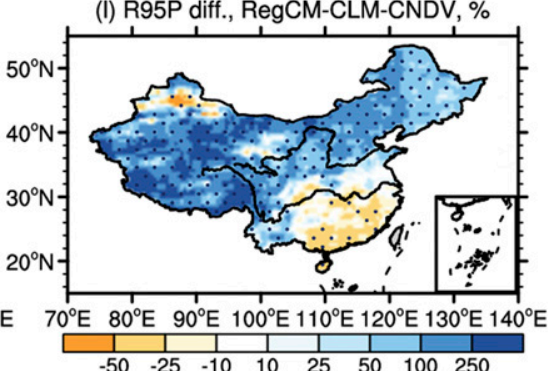

FIG. 11. As in Fig. 10, but for precipitation-related extremes: (a)-(d) CDD (days and \%), (e)-(h) RX5day (mm and \%), and (i)-(l) R95P (mm and \%).

Liu et al. 2014), a model with satellite phenology (e.g., RegCM-CLM) will be sufficient; when the focus is on vegetation feedback at the subseasonal to interannual time scales (e.g., Kim and Wang 2007; Green et al. 2017), a model with predictive phenology will be required (e.g., RegCM-CLM-CN). For long-term climate change studies, models with dynamic vegetation will be a necessity, as changes of vegetation distribution and structure in response to warming and $\mathrm{CO}_{2}$ concentration changes are expected to be large over the typical time frame of climate projections (e.g., half to one century) (e.g., Wang et al. 2011; Yu et al. 2016; Erfanian et al. 2016).
The primary focus of this study is on how different treatments of vegetation in the model influence the model performance in capturing the mean and variability of regional climate, and the differences in vegetation treatment pertain to whether vegetation phenology is predicted or prescribed and whether vegetation distribution is predicted or prescribed. Therefore, the results of this study necessarily are subject to uncertainties in the parameters and parameterizations related to not only vegetation physiological, phenological, and demographic responses (each functioning at the subdaily, seasonal, and decadal time scales, respectively) but also land-atmosphere 
TABLE 3. Spatial correlation coefficient (SCOR) and root-mean-square error (RMSE) between observation and the RegCM-CLM, RegCM-CLM-CN, and RegCM-CLM-CN-DV simulations, for temperature- and precipitation-related climate extremes. The SCORs are all significant at the $95 \%$ confidence level.

\begin{tabular}{|c|c|c|c|c|c|c|}
\hline \multirow[b]{2}{*}{ Indices } & \multicolumn{3}{|c|}{ SCOR } & \multicolumn{3}{|c|}{ RMSE } \\
\hline & RegCM-CLM & RegCM-CLM-CN & RegCM-CLM-CN-DV & RegCM-CLM & RegCM-CLM-CN & RegCM-CLM-CN-DV \\
\hline SU (days) & 0.97 & 0.97 & 0.97 & 15 & 16 & 17 \\
\hline $\operatorname{TXx}\left({ }^{\circ} \mathrm{C}\right)$ & 0.98 & 0.98 & 0.98 & 2.0 & 2.0 & 1.8 \\
\hline $\mathrm{TNn}\left({ }^{\circ} \mathrm{C}\right)$ & 0.91 & 0.91 & 0.90 & 7.5 & 7.5 & 8.9 \\
\hline CDD (days) & 0.37 & 0.40 & 0.53 & 71 & 72 & 66 \\
\hline RX5day(mm) & 0.77 & 0.76 & 0.77 & 50 & 45 & 46 \\
\hline $\mathrm{R} 95 \mathrm{p}(\mathrm{mm})$ & 0.63 & 0.62 & 0.64 & 147 & 141 & 138 \\
\hline
\end{tabular}

flux exchanges. Numerous studies in the past two decades have documented a high degree of model dependence in land-atmosphere coupling at the subseasonal to seasonal time scales, with an overwhelming focus on the coupling between soil moisture and atmosphere (including both precipitation and temperature) (e.g., Koster et al. 2004; Wang et al. 2007; Mei and Wang 2012). The strength of soil moisture-atmosphere coupling in an earlier version of RegCM-CLM used in this study was found to be comparable with observational and reanalysis data (Liu et al. 2014). However, because of the lack of representation of vegetation response to climate in many climate models, studies on the strength of vegetation-atmosphere coupling at the subseasonal and seasonal time scales is still at a very early stage (e.g., Kim and Wang 2007, 2012; Koster and Walker 2015), and comparison with (a) Tmp., China, ${ }^{\circ} \mathrm{C}$

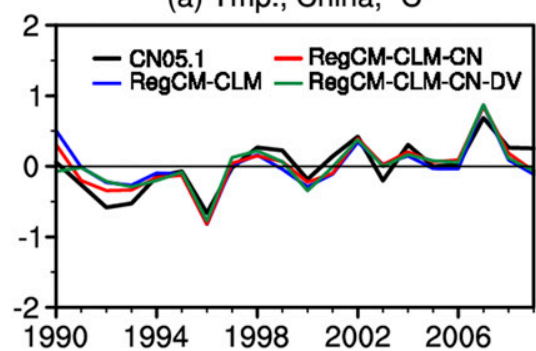

(d) Tmp., East China, ${ }^{\circ} \mathrm{C}$

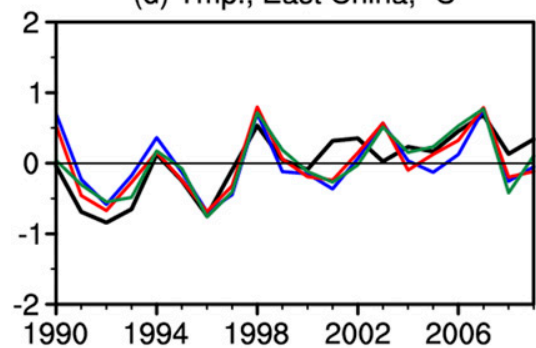

(g) Tmp., Southwest China $1,{ }^{\circ} \mathrm{C}$

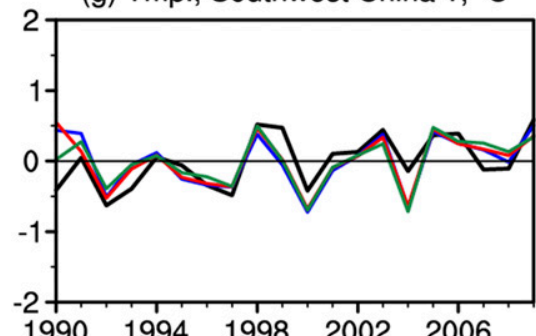

(b) Tmp., Northeast China, ${ }^{\circ} \mathrm{C}$

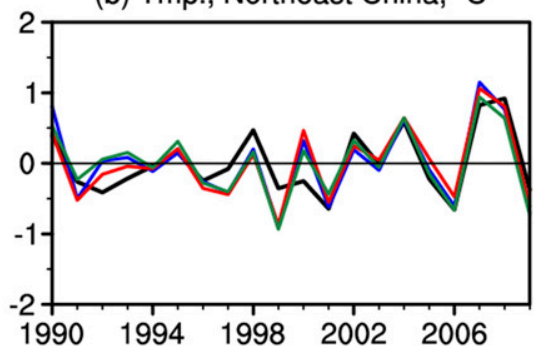

(e) Tmp., Central China, ${ }^{\circ} \mathrm{C}$

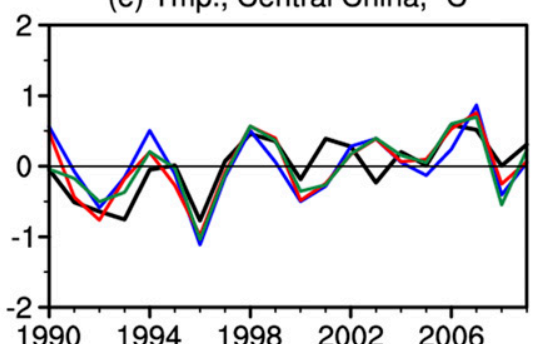

(h) Tmp., Southwest China $2,{ }^{\circ} \mathrm{C}$

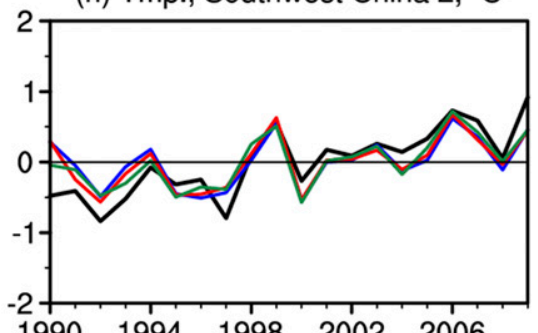

(c) Tmp., North China, ${ }^{\circ} \mathrm{C}$

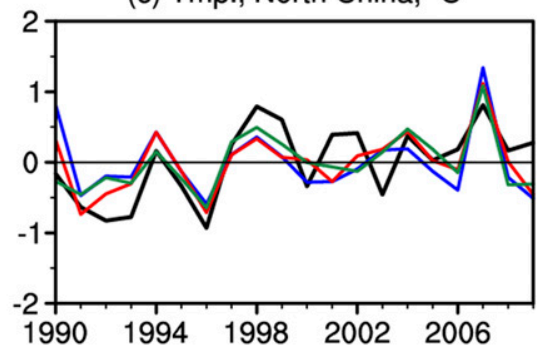

(f) Tmp., South China, ${ }^{\circ} \mathrm{C}$

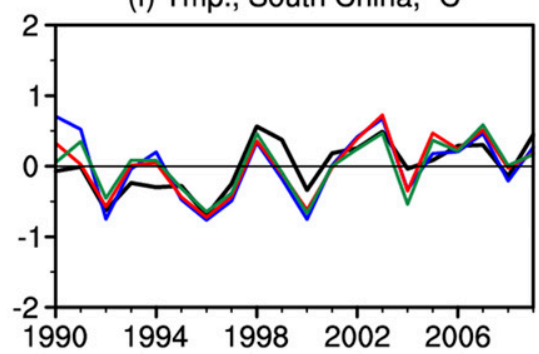

(i) Tmp., Northwest China, ${ }^{\circ} \mathrm{C}$

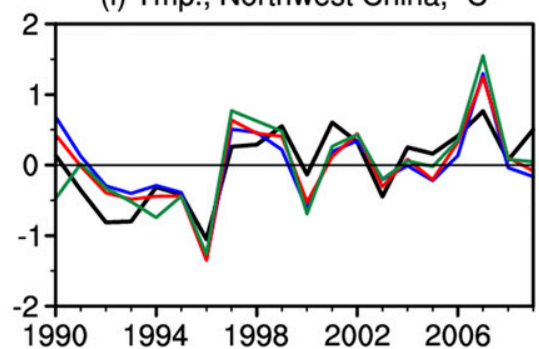

FIG. 12. Temperature anomalies averaged over the entirety of China and its eight subregions in 1990-2009 ( $\left.{ }^{\circ} \mathrm{C}\right)$ (black line: CN05.1, blue line: RegCM-CLM, red line: RegCM-CLM-CN, and green line: RegCM-CLM-CN-DV). 
TABLE 4. Time correlation coefficient (TCOR) between observations and the RegCM-CLM, RegCM-CLM-CN, and RegCM-CLM-CN-DV simulations, for temperature and precipitation over China and its eight subregions. Bold font indicates the strongest correlation(s) of the three, and italic font indicates values that are not significant at the $95 \%$ confidence level.

\begin{tabular}{|c|c|c|c|c|c|c|}
\hline \multirow[b]{2}{*}{ Region } & \multicolumn{3}{|c|}{ Temperature } & \multicolumn{3}{|c|}{ Precipitation } \\
\hline & RegCM-CLM & RegCM-CLM-CN & RegCM-CLM-CN-DV & RegCM-CLM & RegCM-CLM-CN & RegCM-CLM-CN-DV \\
\hline NEC & 0.84 & 0.84 & 0.84 & 0.75 & 0.74 & 0.77 \\
\hline $\mathrm{NC}$ & 0.48 & 0.66 & 0.70 & 0.62 & 0.42 & 0.48 \\
\hline $\mathrm{EC}$ & 0.62 & 0.75 & 0.78 & 0.66 & 0.65 & 0.69 \\
\hline $\mathrm{CC}$ & 0.60 & 0.73 & 0.76 & 0.33 & 0.37 & 0.36 \\
\hline $\mathrm{SC}$ & 0.72 & 0.79 & 0.75 & 0.63 & 0.66 & 0.61 \\
\hline SWC1 & 0.65 & 0.65 & 0.71 & 0.59 & 0.58 & 0.63 \\
\hline SWC2 & 0.76 & 0.80 & 0.87 & 0.35 & 0.51 & 0.38 \\
\hline NWC & 0.75 & 0.82 & 0.79 & 0.61 & 0.68 & 0.61 \\
\hline China & 0.79 & 0.89 & 0.86 & 0.89 & 0.87 & 0.86 \\
\hline
\end{tabular}

observational data has only recently been attempted thanks to the availability of solar-induced florescence data that promptly capture vegetation stress (Green et al. 2017). Green et al. (2017) found that overall the global Earth system models tend to underestimate the biosphere-atmosphere coupling, and suggested that subseasonal and seasonal climate predictions may greatly benefit from better vegetation characterization. While the good performance of the regional climate model used in our study in capturing the soil moisture-atmosphere coupling is encouraging (Liu et al. 2014), follow-up research should evaluate the model's vegetationatmosphere coupling strength to help identify potential model deficiencies and guide further model development. (a) Pre., China, \%

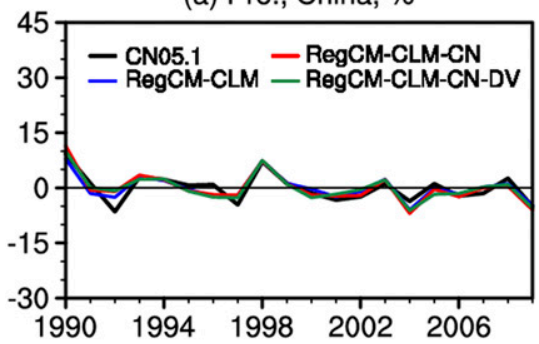

(d) Pre., East China, \%

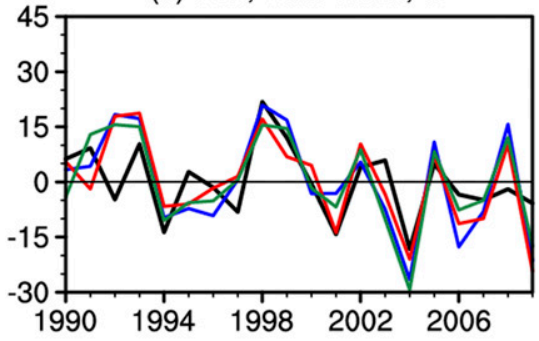

(g) Pre., Southwest China 1, \%

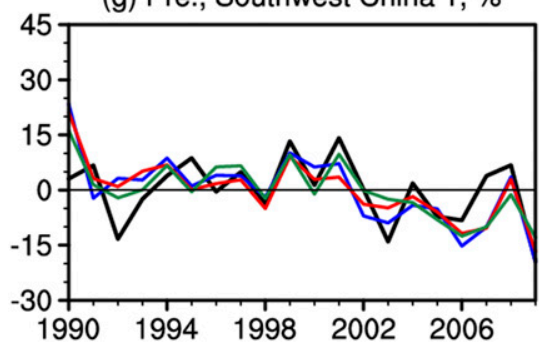

(b) Pre., Northeast China, \%

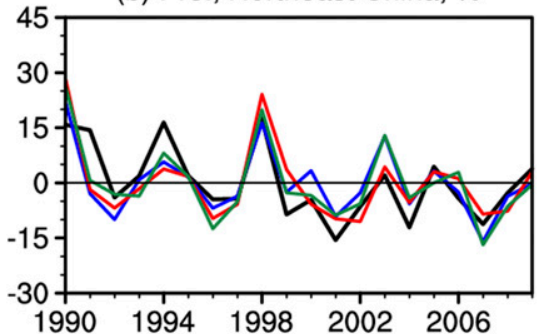

(e) Pre., Central China, \%

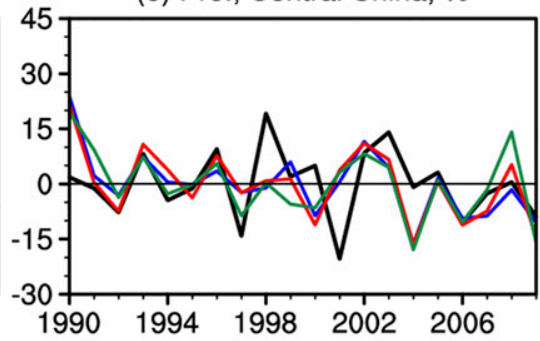

(h) Pre., Southwest China 2, \%

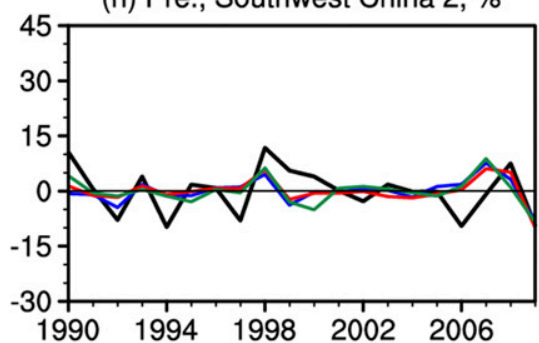

(c) Pre., North China, \%

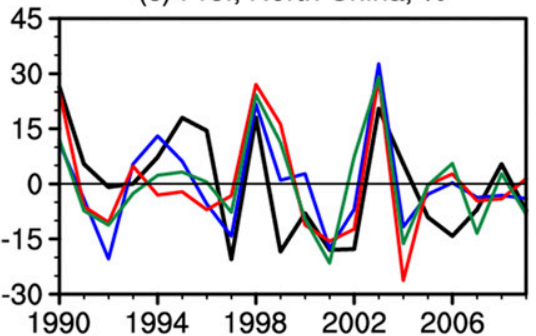

(f) Pre., South China, \%

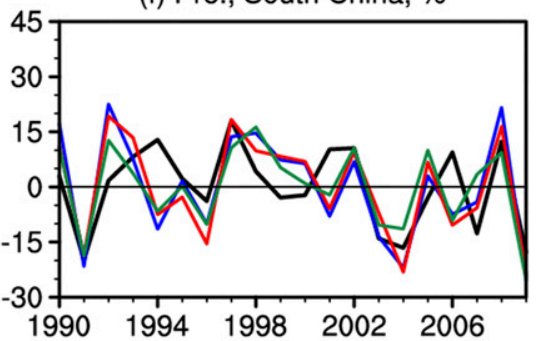

(i) Pre., Northwest China, \%

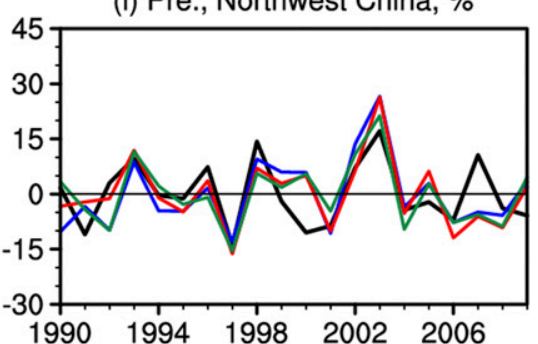

FIG. 13. As in Fig. 12, but for precipitation anomalies (in \%). 
Acknowledgments. This study was jointly supported by National Key Research and Development Program (2017YFA0605002), the General Program of National Natural Science Foundation (41375104, 41675069, and 41575084), and the Climate Change Specific Fund of China (CCSF201808). G. W. was supported by the U.S. National Science Foundation (AGS-1063986). Computational support was made available through an NCAR computing project to the University of Connecticut (UCNN0008).

\section{REFERENCES}

Bonan, G. B., 2008: Forests and climate change: Forcings, feedbacks, and the climate benefits of forests. Science, 320, 14441449, https://doi.org/10.1126/science.1155121.

— S. Levis, S. Sitch, M. Vertenstein, and K. W. Oleson, 2003: A dynamic global vegetation model for use with climate models: Concepts and description of simulated vegetation dynamics. Global Change Biol., 9, 1543-1566, https://doi.org/10.1046/ j.1365-2486.2003.00681.x.

Charney, J. G., 1975: Dynamics of deserts and drought in the Sahel. Quart. J. Roy. Meteor. Soc., 101, 193-202, https://doi.org/ 10.1002/qj.49710142802.

Chen, M., D. Pollarid, and E. J. Barron, 2004: Regional climate change in East Asia simulated by an interactive atmospheresoil-vegetation model. J. Climate, 17, 557-572, https://doi.org/ 10.1175/1520-0442(2004)017<0557:RCCIEA > 2.0.CO;2.

Cho, M.-H., K.-O. Boo, G. M. Martin, J. Lee, and G.-H. Lim, 2015: The impact of land cover generated by a dynamic vegetation model on climate over East Asia in present and possible future climate. Earth Syst. Dyn., 6, 147-160, https://doi.org/10.5194/ esd-6-147-2015.

Cox, P. M., R. A. Betts, C. D. Jones, S. A. Spall, and I. J. Totterdell, 2000: Acceleration of global warming due to carbon-cycle feedbacks in a coupled climate model. Nature, 408, 184-187, https://doi.org/10.1038/35041539.

Dan, L., F. Q. Cao, and R. Gao, 2015: The improvement of a regional climate model by coupling a land surface model with eco-physiological processes: A case study in 1998. Climatic Change, 129, 457-470, https://doi.org/10.1007/s10584-013-0997-8.

Delire, C., J. A. Foley, and S. Thompson, 2004: Long-term variability in a coupled atmosphere-biosphere model. J. Climate, 17, 3947-3959, https://doi.org/10.1175/1520-0442(2004)017<3947: LVIACA $>2.0 . C O ; 2$.

-, N. de Noblet-Ducoudre, A. Sima, and I. Gouirand, 2011: Vegetation dynamics enhancing long-term climate variability confirmed by two models. J. Climate, 24, 2238-2257, https:// doi.org/10.1175/2010JCLI3664.1.

Dickinson, R. E., A. Henderson-Sellers, P. J. Kennedy, and M. F. Wilson, 1986: Biosphere-Atmosphere Transfer Scheme (BATS) for the NCAR Community Climate Model. NCAR/ TN-275+STR, 72 pp., https://doi.org/10.5065/D6668B58.

Ding, Y. H., Q. P. Li, and W. J. Dong, 2005: A numerical simulations study of the impacts of vegetation changes on regional climate in China (in Chinese). Acta Meteor. Sin., 63, 613-621.

Emanuel, K. A., 1991: A scheme for representing cumulus convection in large-scale models. J. Atmos. Sci., 48, 2313 2329, https://doi.org/10.1175/1520-0469(1991)048<2313: ASFRCC $>2.0 . \mathrm{CO} ; 2$.
Erfanian, A., G. L. Wang, M. Yu, and R. Anyah, 2016: Multimodel ensemble simulations of present and future climates over West Africa: Impacts of vegetation dynamics. J. Adv. Model. Earth Syst., 8, 1411-1431, https://doi.org/10.1002/ 2016MS000660.

Foley, J. A., I. C. Prentice, N. Ramankutty, S. Levis, D. Pollard, S. Sitch, and A. Haxeltine, 1996: An integrated biosphere model of land surface processes, terrestrial carbon balance, and vegetation dynamics. Global Biogeochem. Cycles, 10, 603-628, https://doi.org/10.1029/96GB02692.

_ S. Levis, I. C. Prentice, D. Pollard, and S. L. Thompson, 1998: Coupling dynamic models of climate and vegetation. Global Change Biol., 4, 561-579, https://doi.org/10.1046/ j.1365-2486.1998.t01-1-00168.x.

Frich, P., L. V. Alexander, P. Della-Marta, B. Gleason, M. Haylock, A. M. G. Klein Tank, and T. Peterson, 2002: Observed coherent changes in climatic extremes during the second half of the twentieth century. Climate Res., 19, 193-212, https://doi.org/10.3354/cr019193.

Fu, C. B., and H. L. Yuan, 2001: A virtual numerical experiment to understand the impacts of recovering natural vegetation on the summer climate and environmental conditions in East Asia. Chin. Sci. Bull., 46, 1199-1203, https://doi.org/10.1007/ BF02900602.

Gao, J. B., Y. K. Xue, and S. H. Wu, 2013: Potential impacts on regional climate due to land degradation in the Guizhou Karst Plateau of China. Environ. Res. Lett., 8, 044037, https://doi.org/ 10.1088/1748-9326/8/4/044037.

Gao, R., W. J. Dong, and Z. G. Wei, 2008: Simulation and analysis of China climate using two-way interactive atmosphere-vegetation model (RIEMS-AVIM). Adv. Atmos. Sci., 25, 1085-1097, https://doi.org/10.1007/ s00376-008-1085-2.

Gao, X. J., Z. C. Zhao, Y. H. Ding, R. H. Huang, and F. Giorgi, 2001: Climate change due to greenhouse effects in China as simulated by a regional climate model. Adv. Atmos. Sci., 18, 1224-1230, https://doi.org/10.1007/s00376-001-0036-y.

_ , Y. Xu, Z. C. Zhao, J. S. Pal, and F. Giorgi, 2006: On the role of resolution and topography in the simulation of East Asia precipitation. Theor. Appl. Climatol., 86, 173-185, https://doi.org/ 10.1007/s00704-005-0214-4.

_ D. D. Zhang, Z. X. Chen, J. S. Pal, and F. Giorgi, 2007: Land use effects on climate in China as simulated by a regional climate model. Sci. China Ser. D: Earth Sci., 50, 620-628, https://doi.org/10.1007/s11430-007-2060-y.

_ - Y. Shi, R. Y. Song, F. Giorgi, Y. G. Wang, and D. F. Zhang, 2008: Reduction of future monsoon precipitation over China: Comparison between a high resolution RCM simulation and the driving GCM. Meteor. Atmos. Phys., 100, 73-86, https:// doi.org/10.1007/s00703-008-0296-5.

-, D. F. Zhang, J. Wu, F. Giorgi, Z. M. Ji, and Y. G. Wang, 2012: Uncertainties in monsoon precipitation projections over China: Results from two high-resolution RCM simulations. Climate Res., 52, 213-226, https://doi.org/10.3354/cr01084.

,,- Z. Y. Han, M. L. Wang, J. Wu, D. F. Zhang, Y. Xu, and F. Giorgi, 2017: Performance of RegCM4 over major river basins in China. Adv. Atmos. Sci., 34, 441-455, https://doi.org/ 10.1007/s00376-016-6179-7.

Giorgi, F., M. R. Marinucci, and G. T. Bates, 1993a: Development of a second generation regional climate model (REGCM2). Part I: Boundary layer and radiative transfer processes. Mon. Wea. Rev., 121, 2794-2813, https://doi.org/10.1175/ 1520-0493(1993)121<2794:DOASGR > 2.0.CO;2. 
$\_$_ $—$, and —_, 1993b: Development of a second generation regional climate model (REGCM2). Part II: Convective processes and assimilation of lateral boundary conditions. Mon. Wea. Rev., 121, 2814-2832, https://doi.org/ 10.1175/1520-0493(1993)121<2814:DOASGR>2.0.CO;2.

_- Y. Huang, K. Nishizawa, and C. B. Fu, 1999: A seasonal cycle simulation over eastern Asia and its sensitivity to radiative transfer and surface processes. J. Geophys. Res., 104, 64036423, https://doi.org/10.1029/1998JD200052.

— C. Jones, and G. R. Asrar, 2009: Addressing climate information needs at the regional level: The CORDEX framework. WMO Bull., 58, 175-183.

_ - and Coauthors, 2012: RegCM4: Model description and preliminary tests over multiple CORDEX domains. Climate Res. 52, 7-29, https://doi.org/10.3354/cr01018.

Gotangco Castillo, C. K., S. Levis, and P. Thornton, 2012: Evaluation of the new CNDV option of the Community Land Model: Effects of dynamic vegetation and interactive nitrogen on CLM4 means and variability. J. Climate, 25, 3702-3714, https://doi.org/10.1175/JCLI-D-11-00372.1.

Green, J. K., A. G. Konings, S. H. Alemohammad, J. Berry, D. Entekhabi, J. Kolassa, J.-E. Lee, and P. Gentine, 2017: Regionally strong feedbacks between the atmosphere and terrestrial biosphere. Nat. Geosci., 10, 410-414, https://doi.org/ 10.1038/ngeo2957.

Holtslag, A. A., E. I. De Bruijn, and H. L. Pan, 1990: A high resolution air mass transformation model for short-range weather forecasting. Mon. Wea. Rev., 118, 1561-1575, https://doi.org/ 10.1175/1520-0493(1990)118<1561:AHRAMT>2.0.CO;2.

Ji, Z. M., S. C. Kang, Z. Y. Cong, Q. G. Zhang, and T. D. Yao, 2015: Simulation of carbonaceous aerosols over the Third Pole and adjacent regions: Distribution, transportation, deposition, and climatic effects. Climate Dyn., 45, 2831-2846, https://doi.org/ 10.1007/s00382-015-2509-1.

Jiang, D. B., H. J. Wang, and X. M. Lang, 2005: Evaluation of East Asian climatology as simulated by seven coupled models. $A d v$. Atmos. Sci., 22, 479-495, https://doi.org/10.1007/BF02918482.

, Y. Zhang, and X. M. Lang, 2011: Vegetation feedback under future warming. Theor. Appl. Climatol., 106, 211-227, https:// doi.org/10.1007/s00704-011-0428-6.

Ju, L. X., and H. J. Wang, 2006: Modern climate over East Asia simulated by a regional climate model nested in a global gridpoint general circulation model (in Chinese). Chin. J. Geophys., 49, 52-60.

Kiehl, J. T., J. J. Hack, G. B. Bonan, B. A. Boville, D. L. Williamson, and P. J. Rasch, 1998: The National Center for Atmospheric Research Community Climate Model: CCM3. J. Climate, 11, 1131-1149, https://doi.org/10.1175/1520-0442(1998)011<1131: TNCFAR $>2.0 . \mathrm{CO} ; 2$.

Kim, Y. J., and G. L. Wang, 2007: Impact of vegetation feedback on the response of precipitation to antecedent soil moisture anomalies over North America. J. Hydrometeor., 8, 534-550, https://doi.org/10.1175/JHM612.1.

__ and _ 2012: Soil moisture-vegetation-precipitation feedback over North America: Its sensitivity to soil moisture climatology. J. Geophys. Res., 117, D18115, https://doi.org/ 10.1029/2012JD017584.

Koster, R. D., and G. K. Walker, 2015: Interactive vegetation phenology, soil moisture, and monthly temperature forecasts. J. Hydrometeor., 16, 1456-1465, https://doi.org/10.1175/ JHM-D-14-0205.1.

_ and Coauthors, 2004: Regions of strong coupling between soil moisture and precipitation. Science, 305, 1138-1140, https:// doi.org/10.1126/science.1100217.
Lawrence, P. J., and T. N. Chase, 2007: Representing a new MODIS consistent land surface in the Community Land Model (CLM 3.0). J. Geophys. Res., 112, G01023, https:// doi.org/10.1029/2006JG000168.

, and Coauthors, 2011: Parameterization improvements and functional and structural advances in Version 4 of the Community Land Model. J. Adv. Model. Earth Syst., 3, M03001, https://doi.org/10.1029/2011MS00045.

Liu, D., G. L. Wang, R. Mei, Z. Yu, and H. H. Gu, 2014: Diagnosing soil moisture-atmosphere feedback at the seasonal and subseasonal time scales in Asia. J. Hydrometeor., 15, 320-339, https://doi.org/10.1175/JHM-D-13-0104.1.

Liu, Z., M. Notaro, J. Kutzback, and N. Z. Liu, 2006: Assessing global vegetation-climate feedbacks from observations. J. Climate, 19, 787-814, https://doi.org/10.1175/JCLI3658.1.

Lu, L., R. A. Pielke Sr., G. E. Liston, W. Parton, D. Ojima, and M. Hartman, 2001: Implementation of a two-way interactive atmospheric and ecological model and its application to the central United States. J. Climate, 14, 900-919, https://doi.org/ 10.1175/1520-0442(2001)014<0900:IOATWI >2.0.CO;2.

Martin, G. M., and R. C. Levine, 2012: The influence of dynamic vegetation on the present-day simulation and future projections of the South Asian summer monsoon in the HadGEM2 family. Earth Syst. Dyn., 3, 245-261, https://doi.org/ 10.5194/esd-3-245-2012.

McPherson, R. A., 2007: A review of vegetation-atmosphere interactions and their influences on mesoscale phenomena. Prog. Phys. Geogr., 31, 261-285, https://doi.org/10.1177/ 0309133307079055.

Mei, R., and G. L. Wang, 2012: Summer land-atmosphere coupling strength in the United States: Comparison among observations, reanalysis data, and numerical models. J. Hydrometeor., 13, 1010-1022, https://doi.org/10.1175/JHM-D-11-075.1.

,-- , and H. H. Gu, 2013: Summer land-atmosphere coupling strength over the United States: Results from the regional climate model RegCM4.0-CLM3.5. J. Hydrometeor., 14, 946-962, https://doi.org/10.1175/JHM-D-12-043.1.

Neilson, R. P., 1986: High-resolution climatic analysis and southwest biogeography. Science, 232, 27-34, https://doi.org/ 10.1126/science.232.4746.27.

Nemani, R. R., C. D. Keeling, H. Hashimoto, W. M. Jolly, S. C. Piper, C. J. Turker, R. B. Myneni, and S. W. Running, 2003: Climate-driven increases in global terrestrial net primary production from 1982 to 1999. Science, 300, 1560-1563, https:// doi.org/10.1126/science.1082750.

New, M., D. Lister, M. Hulme, and I. Makin, 2002: A highresolution data set of surface climate over global land areas. Climate Res., 21, 1-25, https://doi.org/10.3354/cr021001.

O'ishi, R., A. Abe-Ouchi, I. C. Prentice, and S. Sitch, 2009: Vegetation dynamics and plant $\mathrm{CO}_{2}$ responses as positive feedbacks in a greenhouse world. Geophys. Res. Lett., 36, L11706, https://doi.org/10.1029/2009GL038217.

Pal, J. S., E. E. Small, and E. A. Eltahir, 2000: Simulation of regional-scale water and energy budgets: Representation of subgrid cloud and precipitation processes within RegCM. J. Geophys. Res., 105, 29579-29 594, https://doi.org/10.1029/ 2000JD900415.

- and Coauthors, 2007: Regional climate modeling for the developing world: The ICTP RegCM3 and RegCNET. Bull. Amer. Meteor. Soc., 88, 1395-1409, https://doi.org/10.1175/ BAMS-88-9-1395.

Pielke, R. A., R. Avissar, M. Raupach, A. J. Dolman, X. Zeng, and A. S. Denning, 1998: Interactions between the atmosphere and 
terrestrial ecosystems: Influence on weather and climate. Global Change Biol., 4, 461-475, https://doi.org/10.1046/ j.1365-2486.1998.t01-1-00176.x.

Schwartz, M. D., and T. R. Karl, 1990: Spring phenology: Nature's experiment to detect the effect of "green-up" on surface maximum temperatures. Mon. Wea. Rev., 118, 883-890, https://doi.org/ 10.1175/1520-0493(1990)118<0883:SPNETD > 2.0.CO;2.

Sellers, P. J., Y. Mintz, Y. C. Sud, and A. Dalcher, 1986: A Simple Biosphere model $(\mathrm{SiB})$ for use within general circulation models. J. Atmos. Sci., 43, 505-531, https://doi.org/10.1175/ 1520-0469(1986)043<0505:ASBMFU > 2.0.CO;2.

Shi, Y., X. J. Gao, J. Wu, and F. Giorgi, 2011: Changes in snow cover over China in the 21st century as simulated by a high resolution regional climate model. Environ. Res. Lett., 6, 045401, https://doi.org/10.1088/1748-9326/6/4/045401.

Stenseth, N. C., A. Mysterud, G. Ottersen, J. W. Hurrell, K.- S. Chan, and M. Lima, 2002: Ecological effects of climate fluctuations. Science, 297, 1292-1296, https://doi.org/10.1126/ science.1071281.

Sitch, S., and Coauthors, 2003: Evaluation of ecosystem dynamics, plant geography and terrestrial carbon cycling in the LPJ dynamic global vegetation model. Global Change Biol., 9, 161185, https://doi.org/10.1046/j.1365-2486.2003.00569.x.

Swann, A. L., I. Y. Fung, and J. C. Chiang, 2012: Mid-latitude afforestation shifts general circulation and tropical precipitation. Proc. Natl. Acad. Sci. USA, 109, 712-716, https:// doi.org/10.1073/pnas.1116706108.

Taylor, K. E., B. J. Stouffer, and G. A. Meehl, 2012: An overview of CMIP5 and the experiment design. Bull. Amer. Meteor. Soc., 93, 485-498, https://doi.org/10.1175/BAMS-D-11-00094.1.

Tölle, M. H., S. Engler, and H.-J. Panitz, 2017: Impact of abrupt land cover changes by tropical deforestation on Southeast Asian climate and agriculture. J. Climate, 30, 2587-2600, https://doi.org/10.1175/JCLI-D-16-0131.1.

Uppala, S. M., D. Dee, S. Kobayashi, P. Berrisford, and A. Simmons, 2008: Towards a climate data assimilation system: Status update of ERA-Interim. ECMWF Newsletter, No. 115, ECMWF, Reading, United Kingdom, 12-18.

Wang, G. L., 2004: A conceptual modeling study on biosphereatmosphere interactions and its implications for physically based climate modeling. J. Climate, 17, 2572-2583, https://doi.org/ 10.1175/1520-0442(2004)017<2572:ACMSOB > 2.0.CO;2.

—, and E. A. B. Eltahir, 2000: Biosphere-atmosphere interactions over West Africa. I: Development and validation of a coupled dynamic model. Quart. J. Roy. Meteor. Soc., 126, 1239-1260, https://doi.org/10.1002/qj.49712656503.

— Y Y. J. Kim, and D. G. Wang, 2007: Quantifying the strength of soil moisture-precipitation coupling and its sensitivity to changes in surface water budget. J. Hydrometeor., 8, 551-570, https://doi.org/10.1175/JHM573.1.

, S. S. Sun, and R. Mei, 2011: Vegetation dynamics contributes to the multi-decadal variability of precipitation in the Amazon region. Geophys. Res. Lett., 38, L19703, https://doi.org/ 10.1029/2011GL049017.

—, Y. Miao, J. S. Pal, R. Mei, G. B. Bonan, S. Levis, and P. E. Thornton, 2016: On the development of a coupled regional climate-vegetation model RCM-CLM-CN-DV and its validation in Tropical Africa. Climate Dyn., 46, 515-539, https://doi.org/10.1007/s00382-015-2596-z.

Winter, J. M., J. S. Pal, and E. A. B. Eltahir, 2009: Coupling of integrated biosphere simulator to Regional Climate Model version 3. J. Climate, 22, 2743-2757, https://doi.org/10.1175/ 2008JCLI2541.1.
Woodward, F. I., 1987: Climate and Plant Distribution. Cambridge University Press, $188 \mathrm{pp}$.

Wu, J., and X. J. Gao, 2013: A gridded daily observation dataset over China region and comparison with the other datasets (in Chinese). Chin. J. Geophys., 56, 1102-1111.

Wu, M., G. Schurgers, M. Rummukainen, B. Smith, P. Samuelsson, C. Jansson, J. Siltberg, and W. May, 2016: Vegetation-climate feedbacks modulate rainfall patterns in Africa under future climate change. Earth Syst. Dyn., 7, 627-647, https://doi.org/ 10.5194/esd-7-627-2016.

,,-- A. Ahlström, M. Rummukainen, P. A. Miller, B. Smith, and W. May, 2017: Impacts of land use on climate and ecosystem productivity over the Amazon and the South American continent. Environ. Res. Lett., 12, 054016, https://doi.org/ 10.1088/1748-9326/aa6fd6.

Xu, Y., X. J. Gao, Y. Shen, C. H. Xu, Y. Shi, and F. Giorgi, 2009: A daily temperature dataset over China and its application in validating a RCM simulation. Adv. Atmos. Sci., 26, 763-772, https://doi.org/10.1007/s00376-009-9029-z.

-, , and F. Giorgi, 2010: Upgrades to the reliability ensemble averaging method for producing probabilistic climatechange projections. Climate Res., 41, 61-81, https://doi.org/ $10.3354 / \mathrm{cr} 00835$.

— J. Wu, Y. Shi, B. T. Zhou, R. K. Li, and J. Wu, 2015: Change in extreme climate events over China based on CMIP5. At mos. Oceanic Sci. Lett., 8, 185-192, https://doi.org/10.1080/ 16742834.2015.11447258.

Xue, Y. K., 1996: The impact of desertification in the Mongolian and the Inner Mogolian grassland on the regional climate. J. Climate, 9, 2173-2189, https://doi.org/10.1175/ 1520-0442(1996)009<2173:TIODIT>2.0.CO;2.

_ _ F. De Sales, R. Vasic, and S. Prince, 2010: Global and seasonal assessment of interactions between climate and vegetation biophysical processes: A GCM study with different land-vegetation representations. J. Climate, 23, 1411-1433, https://doi.org/10.1175/2009JCLI3054.1.

Ye, D. Z., and G. X. Wu, 1998: The role of the heat source of the Tibetan Plateau in the general circulation. Meteor. Atmos. Phys., 67, 181-198, https://doi.org/10.1007/BF01277509.

Yu, E. T., H. J. Wang, and J. Q. Sun, 2010: A quick report on a dynamical downscaling simulation over China using the nested model. Atmos. Oceanic Sci. Lett., 3, 325-329, https:/doi.org/ 10.1080/16742834.2010.11446886.

Yu, M., G. L. Wang, D. Parr, and K. F. Ahmed, 2014: Future changes of the terrestrial ecosystem based on a dynamic vegetation model driven with RCP8.5 climate projections from 19 GCMs. Climatic Change, 127, 257-271, https://doi.org/10.1007/s10584-014-1249-2.

and J. S. Pal, 2016: Effects of vegetation feedback on future climate change over West Africa. Climate Dyn., 46, 3669-3688, https://doi.org/10.1007/s00382-015-2795-7.

Zhang, D. F., X. J. Gao, Y. Shi, F. Giorgi, and W. J. Dong, 2010: Agricultural land use effects on climate over China as simulated by a regional climate model. Acta Meteor. Sin., 24, 215-224.

,-- , and J. H. Ma, 2015: Analysis of summer climate over China from hindcast experiments by CCSM4.0 and RegCM4.4 models (in Chinese). Climatic Environ. Res., 20, 307-318.

Zhang, X. B., L. Alexander, G. C. Hegerl, P. Jones, A. K. Tank, T. C. Peterson, B. Trewin, and F. W. Zwiers, 2011: Indices for monitoring changes in extremes based on daily temperature and precipitation data. Wiley Interdiscip. Rev.: Climate Change, 2, 851-870, https://doi.org/10.1002/wcc.147.

Zhang, X. L., Z. Xiong, X. Z. Zhang, Y. Shi, J. Y. Liu, Q. Q. Shao, and X. D. Yan, 2016: Using multi-model ensembles to improve 
the simulated effects of land use/cover change on temperature: A case study over northeast China. Climate Dyn., 46, 765-778, https://doi.org/10.1007/s00382-015-2611-4.

Zheng, Y. Q., Y. F. Qian, M. Q. Miao, G. Yu, Y. S. Kong, and D. H. Zhang, 2002a: The effects of vegetation change on regional climate I: Simulation results (in Chinese). Acta Meteor. Sin., 60, 1-16.

$-,-,-,-\longrightarrow, \ldots$, and,$--2002 \mathrm{~b}$ : The effects of vegetation change on regional climate II: Mechanisms (in Chinese). Acta Meteor. Sin., 60, 17-29.
Zhu, X. F., W. Q. Zhu, J. S. Zhang, and Y. Z. Pan, 2014: Mapping irrigated areas in China from remote sensing and statistical data. IEEE J. Sel. Top. Appl. Earth Obs. Remote Sens., 7, 4490-4504, https://doi.org/10.1109/JSTARS.2013.2296899.

Zou, L. W., and T. J. Zhou, 2013: Near future (2016-40) summer precipitation changes over China as projected by a regional climate model (RCM) under the RCP8.5 emissions scenario: Comparison between RCM downscaling and the driving GCM. Adv. Atmos. Sci., 30, 806-818, https://doi.org/10.1007/ s00376-013-2209-x. 